\title{
Trends in U.S. Working-Age non-Hispanic White Mortality: Rural-Urban and Within-Rural Differences
}

\author{
Shannon M. Monnat ${ }^{1}$ D
}

Received: 28 January 2020 / Accepted: 24 August 2020 / Published online: 4 September 2020 (c) Springer Nature B.V. 2020

\begin{abstract}
After decades of lower or comparable mortality rates in rural than in urban areas of the U.S., numerous studies have documented a rural mortality penalty that started in the 1990s and has grown since the mid-2000s. The widening of the gap appears to be especially pronounced among non-Hispanic (NH) whites. However, the rural U.S. is not monolithic, and some rural places have experienced much larger mortality rate increases than others over the past 30 years. Drawing on restricted mortality files from the National Vital Statistics System (NVSS), I examine metro versus nonmetro and intra-nonmetro (divisional and economic dependency) all-cause and cause-specific mortality trends among working-age (25-64) NH white males and females, 1990-2018. Results show that the nonmetro mortality penalty is wide and growing and is pervasive across multiple disease and injury categories. Trends for females are particularly concerning. Smaller nonmetro declines in mortality from cancers and cardiovascular disease (throughout the 1990s and 2000s) and larger increases in metabolic and respiratory diseases, suicide, alcohol-related, and mental/behavioral disorders (throughout the 2010s) collectively drove the growth in the nonmetro disadvantage. There are also large divisional disparities (which are growing for females), with particularly poor trends in New England, South Atlantic, ES Central, WS Central, and Appalachia and more favorable trends in the Mid-Atlantic, Mountain, and Pacific. Mining-dependent counties have diverged from the other economic dependency types since the mid-2000s due to multiple causes of death, whereas farming counties have comparatively lower mortality rates. High and rising mortality rates across a variety of causes and rural places, some of which have been occurring since the 1990s and others that emerged more recently, suggest that there is not one underlying explanation. Instead, systemic failures across a variety of institutions and policies have contributed to rural America's troubling mortality trends generally and within-rural disparities more specifically.
\end{abstract}

Electronic supplementary material The online version of this article (https://doi.org/10.1007/s1111 3-020-09607-6) contains supplementary material, which is available to authorized users.

Extended author information available on the last page of the article 
Keywords Mortality $\cdot$ Rural $\cdot$ Nonmetro $\cdot$ Population health $\cdot$ Deaths of despair $\cdot$ NH whites

Numerous studies have documented a rural mortality penalty that started in the 1990s and has grown since the mid-2000s (Cosby et al. 2008, 2019; Elo et al. 2019; James 2014; James and Cossman 2017; Singh and Siahpush 2014; Vierboom et al. 2019). Although the rural-urban mortality gap has widened across all major racial/ ethnic groups over the past 20 years, it has widened the most among working-age non-Hispanic (NH) whites (NCHS 2020). These recent trends led some commentators to refer to rural America as the new "inner city" (Adamy and Overberg 2017). However, the rural U.S. is not monolithic, and while mortality rates have increased in some rural places over the past 30 years, they have declined in others.

Drawing on restricted mortality files from the National Vital Statistics System (NVSS), this study expands the existing literature on rural mortality trends in several ways. First, this paper updates trends using the most recently available data (2018 at the time of submission). Second, I describe differences in trends across different Census divisions and categories of economic dependency for rural counties. Third, to gain insight into the structural factors that may be driving trends, I examine 15 specific causes of death and decompose the contributions of these causes to rising all-cause mortality to identify which cause(s) have contributed most to the growth in rural-urban and within-rural disparities. Finally, a major contribution of this paper is the disaggregation of overall changes in cause-specific mortality by decade (1990s, 2000s, 2010), revealing the periods during which specific causes of death exhibited the largest declines and increases. These analyses can help to provide insights into the long- vs. short-term upstream drivers of these trends.

\section{What We Know about Within-Rural Differences in Mortality}

Fortunately, research on metropolitan status differences in mortality has moved beyond the rural-urban binary to examine within-rural differences. The general consensus from this research is that mortality rates vary considerably across different parts of rural America. Using the Economic Research Service's (ERS's) nine-category rural-urban continuum codes (RUCCs) to examine mortality trends from 1968 to 2007, James (2014) found that the rural mortality penalty existed for all rural classifications, but medium-sized nonmetro counties adjacent to metro areas were the worst off, whereas the most remote rural counties exhibited a favorable mortality profile. James and Cossman (2017) similarly found that both white and black mortality rates were comparatively higher in medium-sized nonmetro counties and lower in the smallest nonmetro counties. James et al. (2018) combined RUCCs and the nine Census divisions, finding that persistently high mortality was most heavily concentrated in rural counties in the East South Central division. Murray et al. (2006) divided the U.S. into eight Americas based on race, region, and population density, finding comparatively high life expectancy (LE) in the Great Plains and low 
LE in the Deep South. Vierboom et al. (2019) and Elo et al. (2019) combined metropolitan status and geographic region to create 40 spatial units to examine LE trends from 1990 to 2016, finding that areas with higher LE at the beginning of the period enjoyed larger LE gains. They also found divergent trends between large central metro areas on the coasts and nonmetro areas in Appalachia and the south.

A few of these studies also examined trends in cause-specific mortality, finding larger increases or smaller declines in nonmetro areas in several causes of death over the past two decades, including suicide (Kegler et al. 2017), heart disease, cancer, unintentional injury, and respiratory diseases (Garcia et al. 2017; Vierboom et al. 2019). Using data from 1969 to 2009, Singh and Siahpush (2014) found that heart disease, unintentional injuries, respiratory diseases, lung cancer, stroke, suicide, and diabetes contributed the most to the growing rural-urban disparity in LE. Focusing on working-age (25-64 year old) NH whites, Stein et al. (2017) attributed most of the increase in rural mortality to drug poisoning, alcohol, and suicide (i.e., the "deaths of despair"), whereas Elo et al. (2019) found that the rural-urban mortality divergence among NH whites was driven by screenable cancers, cardiovascular disease, HIV/AIDS, and influenza/pneumonia.

Given massive changes to the U.S. economy over the past three decades, there are also likely to be important differences in mortality trends across different rural labor markets. Yet, there are no studies showing differences in mortality trends across different types of rural economies. In two recent studies, Monnat (2019) and Rigg et al. (2018) found that drug poisoning mortality rates were highest in mining-dependent and lowest in farming-dependent counties. But much remains to be learned about how other causes of death vary across different rural economies.

\section{Explanations for Diverging Mortality Trends}

The rural mortality penalty is grounded in the literature on ecological factors on population health, which include multiple individual, relational, community, and macro-level conditions that put people at risk of or protect against adverse health outcomes. From an agentic downstream perspective, the rural disadvantage can be explained by worse health behavior profiles, including higher rates of smoking, poor diet, sedentary leisure time, and lower seat belt use (NCHS 2019; Strine et al. 2010). Also downstream, rural residents have less access to health care (including preventive and emergency) and are more likely to be uninsured and delay seeking care (NCHS 2019). Moving upstream, educational attainment is lower, and poverty (including among those who work), underemployment, and informal work rates are higher in rural areas (Jensen et al. 2019; Slack et al. 2020; Thiede et al. 2018a, b).

Beyond these compositional and health care factors, the economic and social factors that have contributed to the rural mortality penalty result from a long process of uneven development, industrial restructuring, and a neoliberal policy regime that has eroded economic stability across much of the U.S., particularly among those without a four-year college degree (Case and Deaton 2017). These long-term economic changes and the shock of the Great Recession (Thiede and Monnat 2016) have been inherently spatial, leading to economic decimation in some places and prosperity in 
others (Brown and Schafft 2011; Lichter and Schafft 2016). Employment restructuring moved many livable-wage production jobs out of places that depended on them and concentrated high-wage high-skill service, finance, and technology-based employment in a small handful of urban cores (Bailey et al. 2014; Brown and Swanson 2003; Lobao 2014; Peters 2013; Smith and Tickamyer 2011). This resulted in fewer and lower-wage employment opportunities for individuals without a college degree and made some places more vulnerable than others to substantial economic downturns during and following the Great Recession (Thiede and Monnat 2016). Many rural areas previously characterized by economic dependence on decent-paying manufacturing and mining employment are now dominated by precarious lowwage service work (Burton et al. 2013; Slack 2014). Selective out-migration of the "best and brightest" (Carr and Kefalas 2009), where healthier and better-resourced young adults leave poor communities to seek out better job opportunities, has intensified the disproportionate geographic clustering of multigenerational economic distress in many rural communities. As a result, while urban coastal cities generally experienced large increases in LE over the past several decades, LE has declined in parts of America's heartland that were once hubs for secure working-class jobs.

\section{The Present Study}

In the analyses that follow, I examine metro versus nonmetro and intra-nonmetro (division, economic dependency) mortality trends among working-age (25-64) $\mathrm{NH}$ whites, 1990-2018. I focus on working-age NH whites because the U.S.'s recent LE decline and long-run divergence from peer countries appear to be due mostly to mortality rate increases in this population (Case and Deaton 2015; Elo et al. 2019; Ho 2013; Woolf and Schoomaker 2019). In addition, mortality trends for NH whites differ considerably from other major racial/ethnic groups. For example, although $\mathrm{NH}$ black mortality rates remain substantially higher than those for $\mathrm{NH}$ whites, mortality rates among working-age NH black males have declined considerably in both metro and nonmetro counties since the early 1990s, and rates among working-age NH black females have declined slightly in metro counties and remained relatively stable in nonmetro counties (see Online Appendix Fig. 2). Conversely, mortality rates have increased among working-age $\mathrm{NH}$ white males and females in nonmetro areas while generally declining in metro areas. Presenting mortality trends with all racial/ethnic groups combined would mask important differences in (a) the magnitude of all-cause and cause-specific mortality rates, (b) trends in rates over the study period, and (c) conclusions about the causes of death that have contributed most to the widening nonmetro mortality penalty since 1990. See Online Appendix Fig. 1 for trends in working-age all-cause mortality rates for all racial/ethnic groups combined by metro status and Fig. 2 for trends for working-age NH blacks alone by metro status.

In addition to examining differences in all-cause mortality trends, a major contribution of this paper is the decomposition of mortality rate changes across 15 causeof-death categories and three decades. Observing trends in specific causes of death during the 1990s, 2000s, and 2010s can help illuminate the potential underlying 
causes and upstream drivers of the rural mortality penalty. Compositional factors certainly matter. Rural areas are home to disproportionately larger shares of populations vulnerable to premature mortality, including the poor, those with lower education, and the disabled. However, population composition alone does not explain the rural mortality penalty (Cosby et al. 2019). Another potential explanation is behavioral risk factors, including smoking, substance use, poor diet, motor vehicle use, and other risky behaviors, which would be captured in causes of death like lung cancer, respiratory diseases, cardiovascular disease, substance use, and other external causes. Contextual factors also matter. One potential contextual explanation is access to and quality of health care. Health insurance rates are lower and health services are more limited in rural than in urban areas. If health care factors are driving rural mortality trends, then we should observe rate increases or lower rates of decline in causes of death that are most amenable to quality screening and treatment (e.g., screenable cancers, HIV/AIDS). Of course, upstream structural conditions like economic and social disadvantage drive both health care and behavioral risk factors. They also increase exposure to various health-harming environments (e.g., dangerous work-place conditions, poor housing quality, exposure to environmental pollutants, and other social determinants of health) and may manifest in multiple causes of death.

\section{Data and Methods}

I use the 1990-2018 Multiple Cause-of-Death micro data files, provided by NCHS (2020) under a data user agreement, to tabulate NH white death counts by cause, sex, age group, county, and year. NH white population counts come from the publicuse Census bridged-race population estimates by 10-year age group, sex, county, and year. I pooled deaths into three-year groupings representing 1990-1992, 2000-2002, 2010-2012, and 2016-2018. Pooling smooths large fluctuations that can occur from small changes in deaths in low-population counties. I calculated all-cause and causespecific mortality rates by sex and age group (25-44 and 45-64). Rates are ageadjusted within each 20 -year age group using 10-year population counts and weights (25-34, 35-44, 45-54, and 55-64). In all analyses, the mortality rates represent ageadjusted rates (deaths per 100,000 population) for the pooled grouping (e.g., all nonmetro males ages 25-44 in New England) rather than average county-level rates. From 1990 to 2018 , NH whites comprised $67.4 \%$ of deaths in metro counties and $81.6 \%$ of deaths in nonmetro counties (author calculations).

The main analyses include 1947 nonmetro counties in the coterminous U.S. Alaska and Hawaii are excluded, as is Allegheny County, VA due to boundary changes between 1990 and 2018. Nonmetro status was based on the 2013 ERS RUCCs. In a similar study of mortality trends, Vierboom et al. (2019) found only negligible differences when applying metro statuses in 1990 or 2006 vs. 2013. In preliminary analysis (available from the author upon request), I also delineated nonmetro counties by whether they are adjacent (RUCCs 4, 6, and 8) or not adjacent (RUCCs 5, 7, and 9) to a metro area. I found negligible differences in mortality levels and trends by adjacency suggesting that metro adjacency may 
not be a useful comparator when examining within-rural differences in mortality trends. Accordingly, I do not discuss differences by adjacency in the paper.

In addition to examining trends in nonmetro mortality rates overall, I also disaggregate by Census division and ERS economic dependency type. The 10 divisions include the nine Census divisions, plus Appalachia, as defined by the Appalachian Regional Commission. Appalachian counties, which include all of WV and counties from 12 other states, are excluded from their overlapping Census divisions. See Online Appendix A Table 1 for a list of states in each division. Economic dependency categories are based on ERS's 1989 classification, and include farming, mining, manufacturing, government, services, and nonspecialized. I used the 1989 classification because it precedes the first year in the mortality time series (1990) and given arguments that contemporary mortality trends, especially the deaths of despair, may be related to economic conditions that started to unfold in the 1980s (Case and Deaton 2017; Monnat 2019; Monnat and Brown 2017). Results from sensitivity analysis using the 2015 economic typology codes were very similar.

I also examine levels and trends in 15 mutually exclusive and exhaustive cause-of-death categories:

- HIV/AIDS

- Non-HIV/AIDS infectious and parasitic diseases

- Liver cancer

- Lung cancer

- Screenable and all other cancers

- Endocrine, nutritional, and metabolic diseases (ENM)

- Hypertensive heart disease

- Ischemic heart disease and other diseases of the circulatory system (including stroke)

- Mental/behavioral disorders and diseases of the nervous system

- Alcoholic liver disease and other alcohol-induced causes

- Drug poisoning

- Suicide

- Other external causes of death

- All other causes

The 'all other causes' category captures ill-defined causes of death or causes that account for a relatively small proportion of deaths in the 25-64-year age group. The ICD-9 (1990-1998) and ICD-10 (1999-2017) codes for all causes are listed in Online Appendix A Table 2. 


\section{Results}

\section{Metro vs. Nonmetro Differences}

Figure 1 shows trends in all-cause mortality rates for $\mathrm{NH}$ white males and females ages 25-44 and 45-64 by metro status, 1990-2018. In all four groups, metro and nonmetro mortality rates were comparable in the early 1990s. The gap began to widen in the late 1990s, as metro mortality rates started to decline (for ages 45-64) and nonmetro mortality rates started to increase (for ages 25-44). The age 25-44 mortality rate increased for both metro and nonmetro males and females, but the increases were larger for nonmetro. Trends are generally comparable when all racial/ ethnic groups are combined (Online Appendix Fig. 1), except metro mortality rates have declined overall, driven by large reductions among NH blacks (Online Appendix Fig. 2). The remainder of this section presents results only for $\mathrm{NH}$ whites.

Between 1990-1992 and 2016-2018, the mortality rates among NH whites increased by 9.6 deaths per 100,000 population among metro males and 30.5 among metro females but increased by 70.1 and 65.0 among nonmetro males and females, respectively (Table 1). This resulted in a nonmetro mortality penalty for ages $25-44$ in 2016-2018 of 51.2 deaths per 100,000 population (gap of 23.3\%) among males and 40.0 deaths per 100,000 population (gap of $34.2 \%$ ) among females. For ages 45-64, metro mortality rates declined throughout the 1990s and most of the 2000s for both males and females. Metro declines began stagnating in the late 2000s and
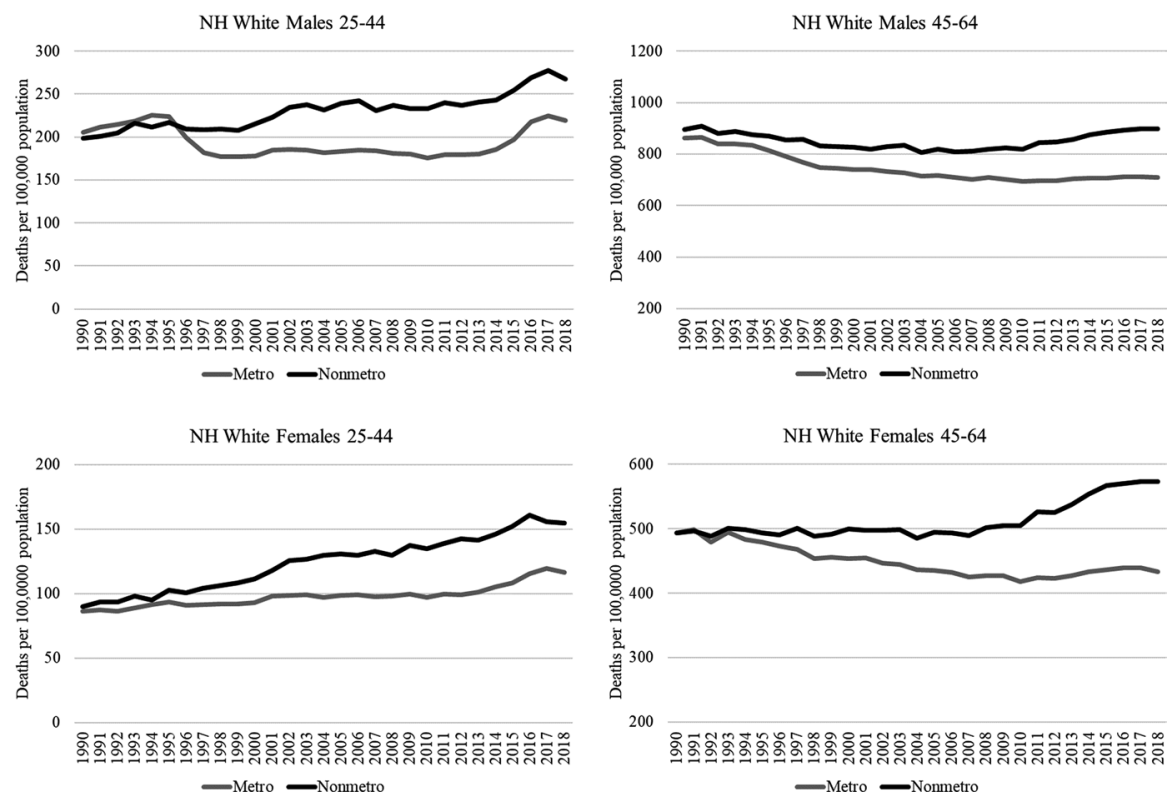

Fig. 1 All-cause mortality rates for non-Hispanic white males and females ages 25-44 and 45-64 by metro status. Rates are age-adjusted; $N=9,211,413$ deaths in metro counties and 2,465,300 deaths in nonmetro counties 
Table 1 Cause-specific mortality rates for metro and nonmetro NH white males and females ages 25-44 and 45-64, 1990-1992 and 2016-2018

\begin{tabular}{|c|c|c|c|c|c|c|c|c|c|c|c|c|c|c|}
\hline & \multicolumn{7}{|c|}{ NH White Males ages 25-44 } & \multicolumn{7}{|c|}{ NH White Females ages 25-44 } \\
\hline & \multicolumn{3}{|c|}{ Metro } & \multicolumn{3}{|c|}{ Nonmetro } & \multirow[b]{2}{*}{\begin{tabular}{|c|}
$\%$ Contribution \\
to Growth in \\
Nonmet \\
Disadvantage
\end{tabular}} & \multicolumn{3}{|c|}{ Metro } & \multicolumn{3}{|c|}{ Nonmetro } & \multirow[b]{2}{*}{$\begin{array}{l}\% \text { Contribution } \\
\text { to Growth in } \\
\text { Nonmet } \\
\text { Disadvantage }\end{array}$} \\
\hline & $\begin{array}{l}1990- \\
1992 \\
\end{array}$ & $\begin{array}{l}2016- \\
2018\end{array}$ & $\begin{array}{c}\text { Abs. } \Delta \text { in } \\
\text { Rate }\end{array}$ & $\begin{array}{l}1990- \\
1992\end{array}$ & $\begin{array}{c}2016- \\
2018 \\
\end{array}$ & $\begin{array}{c}\text { Abs. } \Delta \text { in } \\
\text { Rate }\end{array}$ & & $\begin{array}{l}1990- \\
1992 \\
\end{array}$ & $\begin{array}{l}2016- \\
2018\end{array}$ & $\begin{array}{c}\text { Abs. } \Delta \text { in } \\
\text { Rate }\end{array}$ & $\begin{array}{l}1990- \\
1992\end{array}$ & $\begin{array}{l}2016- \\
2018 \\
\end{array}$ & $\begin{array}{c}\text { Abs. } \Delta \text { in } \\
\text { Rate }\end{array}$ & \\
\hline All Deaths & 210.7 & 220.3 & 9.6 & 201.4 & 271.5 & 70.1 & & 86.7 & 117.2 & 30.5 & 92.3 & 157.2 & 65.0 & \\
\hline \multicolumn{15}{|l|}{ nfectious \& Parasitic Diseases } \\
\hline HIV/AIDS & 39.5 & 1.0 & -38.5 & 10.4 & 1.0 & -9.4 & 48.0 & 2.1 & 0.3 & -1.8 & 0.5 & 0.4 & -0.1 & 4.8 \\
\hline Non-HIV/AIDS & 3.8 & 2.3 & -1.5 & 2.3 & 3.6 & 1.3 & 4.6 & 1.4 & 2.1 & 0.7 & 1.2 & 3.6 & 2.4 & 4.8 \\
\hline \multicolumn{15}{|l|}{ Cancers } \\
\hline Liver Cancer & 0.5 & 0.5 & 0.0 & 0.5 & 0.6 & 0.2 & 0.2 & 0.2 & 0.4 & 0.2 & 0.3 & 0.5 & 0.2 & 0.1 \\
\hline fung Cancer & 4.2 & 1.3 & -2.9 & 4.5 & 2.1 & -2.4 & 0.8 & 3.1 & 1.2 & -1.9 & 3.0 & 2.0 & -1.0 & 2.7 \\
\hline Screenable Cancers & 20.8 & 14.6 & -6.2 & 20.2 & 18.2 & -1.9 & 7.1 & 26.5 & 18.2 & -8.2 & 27.6 & 22.1 & -5.5 & 8.0 \\
\hline \multicolumn{15}{|l|}{ Cardio \& Metabolic } \\
\hline ENM Diseases & 5.0 & 6.3 & 1.3 & 5.5 & 10.0 & 4.5 & 5.2 & 2.9 & 4.4 & 1.4 & 3.2 & 8.2 & 5.0 & 10.3 \\
\hline Hypertensive Disease & 1.1 & 3.8 & 2.7 & 0.7 & 4.4 & 3.7 & 1.6 & 0.3 & 1.5 & 1.2 & 0.3 & 2.1 & 1.8 & 1.7 \\
\hline schemic \& Circulatory & 29.4 & 21.8 & -7.6 & 33.9 & 34.5 & 0.6 & 13.5 & 11.1 & 11.4 & 0.4 & 13.8 & 20.7 & 6.9 & 18.9 \\
\hline \multicolumn{15}{|l|}{ Substances \& Mental Health } \\
\hline Prug Poisoning & 9.6 & 71.0 & 61.4 & 4.8 & 53.8 & 48.9 & -20.5 & 4.2 & 32.6 & 28.4 & 2.6 & 30.2 & 27.5 & -2.6 \\
\hline Alcohol Induced & 5.0 & 6.6 & 1.6 & 3.4 & 7.3 & 3.9 & 3.7 & 1.8 & 4.0 & 2.1 & 1.0 & 4.1 & 3.1 & 2.8 \\
\hline Suicide & 22.5 & 31.1 & 8.6 & 25.3 & 43.2 & 17.8 & 15.2 & 4.6 & 7.7 & 3.1 & 4.6 & 9.4 & 4.8 & 4.9 \\
\hline Mental \& Nervous System & 6.9 & 10.0 & 3.1 & 6.4 & 11.3 & 4.9 & 3.0 & 3.4 & 6.6 & 3.2 & 3.5 & 8.1 & 4.6 & 4.0 \\
\hline \multicolumn{15}{|l|}{ Pther Causes of Death } \\
\hline Respiratory Diseases & 4.5 & 4.0 & -0.5 & 4.0 & 5.9 & 1.9 & 3.9 & 3.0 & 3.7 & 0.8 & 2.8 & 6.7 & 3.9 & 9.1 \\
\hline Pther External & 44.4 & 34.5 & -9.9 & 69.2 & 59.8 & -9.4 & 0.9 & 14.4 & 12.7 & -1.7 & 21.1 & 23.7 & 2.6 & 12.4 \\
\hline \multirow[t]{4}{*}{ All other Causes } & 13.6 & 11.5 & -2.1 & 10.3 & 16.0 & 5.7 & 12.8 & 7.7 & 10.3 & 2.6 & 6.5 & 15.3 & 8.8 & 18.0 \\
\hline & \multicolumn{7}{|c|}{ NH White Males ages 45-64 } & \multicolumn{7}{|c|}{ NH White Females ages 45-64 } \\
\hline & & Metro & & & Nonmetro & & & & Metro & & & Nonmetro & & \\
\hline & $\begin{array}{l}1990- \\
1992 \\
\end{array}$ & $\begin{array}{l}2016- \\
2018 \\
\end{array}$ & $\begin{array}{c}\text { Abs. } \Delta \text { in } \\
\text { Rate }\end{array}$ & $\begin{array}{l}1990- \\
1992 \\
\end{array}$ & $\begin{array}{l}2016- \\
2018 \\
\end{array}$ & $\begin{array}{c}\text { Abs. } \Delta \text { in } \\
\text { Rate }\end{array}$ & $\begin{array}{c}\% \text { Contribution } \\
\text { to Growth in } \\
\text { Nonmet } \\
\text { Disadvantage } \\
\end{array}$ & $\begin{array}{l}1990- \\
1992 \\
\end{array}$ & $\begin{array}{l}2016- \\
2018 \\
\end{array}$ & $\begin{array}{c}\text { Abs. } \Delta \text { in } \\
\text { Rate }\end{array}$ & $\begin{array}{l}1990- \\
1992 \\
\end{array}$ & $\begin{array}{l}2016- \\
2018 \\
\end{array}$ & $\begin{array}{c}\text { Abs. } \Delta \text { in } \\
\text { Rate }\end{array}$ & $\begin{array}{c}\% \text { Contribution } \\
\text { to Growth in } \\
\text { Nonmet } \\
\text { Disadvantage } \\
\end{array}$ \\
\hline \begin{tabular}{|l} 
All Deaths \\
\end{tabular} & 855.0 & 711.1 & \begin{tabular}{|l|}
-143.9 \\
\end{tabular} & 894.8 & 896.6 & 1.8 & & 490.4 & 4337.6 & -52.9 & 492.6 & 571.9 & 79.3 & \\
\hline \multicolumn{15}{|l|}{ Infectious \& Parasitic Diseases } \\
\hline HIV/AIDS & 22.2 & 3.8 & -18.4 & 4.5 & 2.2 & -2.3 & 11.1 & 0.9 & 0.7 & -0.2 & 0.3 & 0.5 & 0.2 & 0.4 \\
\hline Non-HIV/AIDS & 9.7 & 16.7 & 7.0 & 8.0 & 21.6 & 13.6 & 4.6 & 6.1 & 12.2 & 6.1 & 5.8 & 16.0 & 10.2 & 3.1 \\
\hline \multicolumn{15}{|l|}{ Cancers } \\
\hline Liver Cancer & 5.1 & 12.7 & 7.6 & 4.6 & 14.6 & 10.0 & 1.6 & 2.2 & 4.2 & 2.0 & 2.5 & 4.8 & 2.3 & 0.2 \\
\hline Lung Cancer & 112.0 & 43.9 & -68.1 & 120.8 & 64.8 & -56.0 & 8.4 & 63.8 & 35.7 & -28.1 & 57.7 & 51.9 & -5.8 & 16.9 \\
\hline Screenable Cancers & 166.8 & 121.6 & -45.3 & 163.0 & 144.9 & -18.1 & 18.6 & 170.3 & 114.0 & -56.4 & 160.4 & 127.9 & -32.6 & 18.0 \\
\hline Cardio \& Metabolic & & & & & & & & & & & & & & \\
\hline Nutritional \& Metabolic & 23.1 & 36.8 & 13.8 & 23.3 & 48.7 & 25.4 & 8.0 & 16.9 & 20.6 & 3.7 & 19.7 & 30.4 & 10.8 & 5.4 \\
\hline Hypertensive Disease & 10.1 & 23.9 & 13.8 & 6.4 & 23.5 & 17.1 & 2.3 & 4.9 & 10.8 & 5.8 & 3.2 & 12.0 & 8.8 & 2.3 \\
\hline Ischemic \& Circulatory & 312.8 & 170.5 & -142.3 & 349.3 & 235.5 & -113.8 & 19.6 & 119.2 & 72.4 & -46.8 & 135.7 & 111.3 & -24.4 & 17.0 \\
\hline \begin{tabular}{|l} 
Substances \& Mental Health \\
\end{tabular} & & & & & & & & & & & & & & \\
\hline Drug Poisoning & 3.7 & 46.2 & 42.5 & 2.1 & 33.7 & 31.6 & -7.5 & 4.2 & 29.1 & 24.9 & 2.6 & 28.5 & 25.9 & 0.7 \\
\hline Alcohol Induced & 16.6 & 26.0 & 9.4 & 15.4 & 28.0 & 12.6 & 2.3 & 5.4 & 12.6 & 7.2 & 4.0 & 11.8 & 7.8 & 0.5 \\
\hline Suicide & 23.2 & 34.1 & 10.9 & 24.3 & 39.4 & 15.0 & 2.8 & 5.5 & 8.6 & 3.1 & 4.7 & 9.3 & 4.6 & 1.1 \\
\hline Mental \& Nervous System & 19.4 & 36.0 & 16.6 & 19.6 & 38.0 & 18.4 & 1.2 & 11.6 & 22.9 & 11.3 & 11.3 & 26.2 & 14.9 & 2.7 \\
\hline Other Causes of Death & & & & & & & & & & & & & & \\
\hline Respiratory & 44.8 & 42.8 & -2.0 & 52.7 & 64.8 & 12.1 & 9.7 & 32.9 & 37.9 & 5.0 & 34.2 & 61.6 & 27.4 & 17.0 \\
\hline Other External & 39.5 & 43.2 & 3.7 & 56.4 & 66.9 & 10.5 & 4.6 & 15.5 & 17.0 & 1.5 & 20.4 & 26.0 & 5.6 & 3.1 \\
\hline All other Causes & 45.8 & 52.9 & 7.0 & 44.4 & 70.0 & 25.7 & 12.8 & 30.8 & 39.0 & 8.1 & 30.2 & 53.8 & 23.5 & 11.7 \\
\hline
\end{tabular}

Rates are age-adjusted and represent deaths per 100,000 population. Abs. $\Delta=$ absolute change in the mortality rate from 1990-1992 to 2016-2018. Light gray shading indicates causes of death for which the rate was lower in 2016-2018 than in 1990-1992. Dark gray shading indicates causes of death for which the rate was higher in 2016-2018 than in 1990-1992. The percent contribution to the growth in the nonmetro disadvantage is calculated by dividing the nonmetro-metro difference in the change in each causespecific mortality rate by the nonmetro-metro difference in the change in the all-cause mortality rate and multiplying by 100

then reversed direction and began to increase slightly in the 2010s. Despite these recent increases, metro mortality rates for ages 45-64 remained lower in the late2010s than they were in the early 1990s. Conversely, nonmetro mortality rates increased for both males and females ages 45-64 between 1990 and 2018. After a period of declining rates in the 1990s, nonmetro male rates were stagnant throughout the 2000s and began to noticeably increase in the 2010s. Nonmetro female rates remained relatively stagnant throughout the 1990s and most of the 2000s, but then began to increase in the late 2000s and continued increasing at a more rapid rate throughout the 2010s. Whereas there was a negligible gap in the mortality rate between metro and nonmetro NH whites ages 45-64 in the early 1990s, by 2016-18, 
the nonmetro mortality penalty had grown to 185.5 deaths per 100,000 population (gap of $26.0 \%$ ) for males and 134.3 (gap of $30.7 \%$ ) for females.

\section{Cause-Specific Contributions to the Growing Rural Mortality Penalty}

Table 1 shows mortality rates for 15 causes of death, the absolute changes in rates from 1990 to 1992 to 2016-2018, and the percent contribution each cause made to the growing nonmetro penalty over this period.

In all four groups, for every cause of death except drug poisoning, rates increased more in nonmetro, declined less in nonmetro, or increased in nonmetro while declining in metro. This means that every cause of death except drug poisoning contributed to the widening nonmetro all-cause mortality penalty over this period.

For nonmetro males ages $25-44$, the mortality rate increased by 70.1 deaths per 100,000 population between 1990-1992 and 2016-2018 (compared to an increase of only 9.6 among metro males ages $25-44$ ), and $81 \%$ of the nonmetro increase was due to increases in drugs, alcohol, suicide, and mental/behavioral disorders (the deaths of despair). HIV/AIDS, suicide, and ischemic and circulatory system diseases were the largest contributors to the growth in the nonmetro-metro gap for males ages 25-44. For example, HIV/AIDS contributed to $48 \%$ of the growth in the nonmetro mortality penalty over this period. This is not because HIV/AIDS increased among nonmetro males, but instead because rates were much higher among metro males at the start of the period, and there was much less room to decline in nonmetro counties. But nonmetro males also experienced a slight increase in mortality from ischemic and circulatory diseases, whereas metro males experienced a decline, contributing to $13.5 \%$ of the growth in the nonmetro mortality penalty. Suicide rates increased among both metro and nonmetro males ages $25-44$, but the increase was over twice as large among nonmetro males, contributing to $15 \%$ of the growth in the nonmetro mortality penalty. A smaller nonmetro decline in screenable cancer mortality, and increases in respiratory disease, other external causes, and the 'all other causes' residual category also contributed appreciably to the growing nonmetro mortality penalty among males in this age group.

Among NH white males ages 45-64, smaller nonmetro declines in lung and screenable cancers, ischemic and circulatory system diseases, and HIV/AIDS, and nonmetro increases in diseases of the respiratory system, ENM diseases, and the residual all other causes category accounted for most of the growing nonmetro mortality disadvantage. Drug poisonings increased more than any other cause of death for both metro and nonmetro males, but the increase was larger for metro males. This was the only cause of death that reduced the nonmetro disadvantage. For all other causes of death that increased in this age group, the increase was larger among nonmetro than among metro males.

Mortality rate increases since the early 1990s among nonmetro females have been startling. For ages 25-44 rates increased in both metro and nonmetro counties, but the increase was over twice as large for nonmetro females. The collective deaths of despair accounted for $56 \%$ of the increase in all-cause mortality in this group. Ischemic and circulatory system diseases, ENM diseases, other external causes, and the all other causes category were the largest contributors to the 
growing nonmetro penalty, collectively accounting for $60 \%$ of the increase in the nonmetro-metro gap. Drug poisoning increased more than any other cause for both metro and nonmetro females ages $25-44$, but the increases were fairly comparable and so did not contribute much to the gap.

Among females ages $45-64$, the mortality rate declined by $10.8 \%$ in metro counties but increased by $16.1 \%$ in nonmetro counties. Lung and screenable cancers and ischemic and circulatory diseases (which declined much less in nonmetro) and respiratory diseases (which increased much more in nonmetro) accounted for nearly $70 \%$ of the growth in the nonmetro mortality penalty. Drug poisoning increased the most for metro females in this age group, whereas respiratory diseases increased the most for nonmetro females. While mortality rates from respiratory diseases increased for both metro and nonmetro females in this age group, the increase for nonmetro females (80\%) is starting.

These trends represent change over a 29-year period, but mortality rate changes are not necessarily linear; certain periods have witnessed larger changes than others in various causes of death. Accordingly, Figs. 2 and 3 decompose these changes by decade. For each cause, the figure shows the absolute change in the mortality rate from 1990-1992 to 2000-2002 (1990s change), 2000-2002 to 2010-2012 (2000s change), and 2010-2012 to 2016-2018 (2010s change). This visualization reveals some concerning trends.

First, most of the decline in mortality from screenable and lung cancers occurred during the 1990s and 2000s, with very small declines in the 2010s. Second, drug mortality increases dwarf increases in other causes of death, but the timing of increases in drug poisoning mortality have not been uniform. Among metro males in both age groups and metro females ages 25-44, most of the increase occurred in the $2010 \mathrm{~s}$, whereas most of the increase among nonmetro males and females occurred in the 1990s and 2000s. The surge in drug poisoning mortality rates in metro areas in the 2010s has been due in large part to the influx of fentanyl (Peters et al. In Press). Third, most of the suicide and alcohol-induced mortality increases occurred in the 2000s and 2010s (rather than the 1990s), suggesting a potential Great Recession effect, but the suicide rate was increasing among nonmetro males ages 25-44 in the 1990s suggesting much longer-term underlying causes than the Great Recession. Fourth, increases in ENM and hypertensive deaths both started in the 1990s, representing a long-term change. Fifth, among nonmetro males and females ages 45-64, major improvements in ischemic and circulatory system mortality rates in the 1990s and 2000s reversed in the 2010s. This same trend did not occur among metro adults. This is troubling given that this is the largest contributor to mortality for males and the second largest for females in this age group. Sixth, declines in mortality from other external causes among young adults (mostly transport accidents) were a 1990s and 2000s public health success story. However, since the early 2010s, there have been increases (albeit small) in mortality rates from other external causes of death across all groups, signaling a reversal of long-term improvements. 


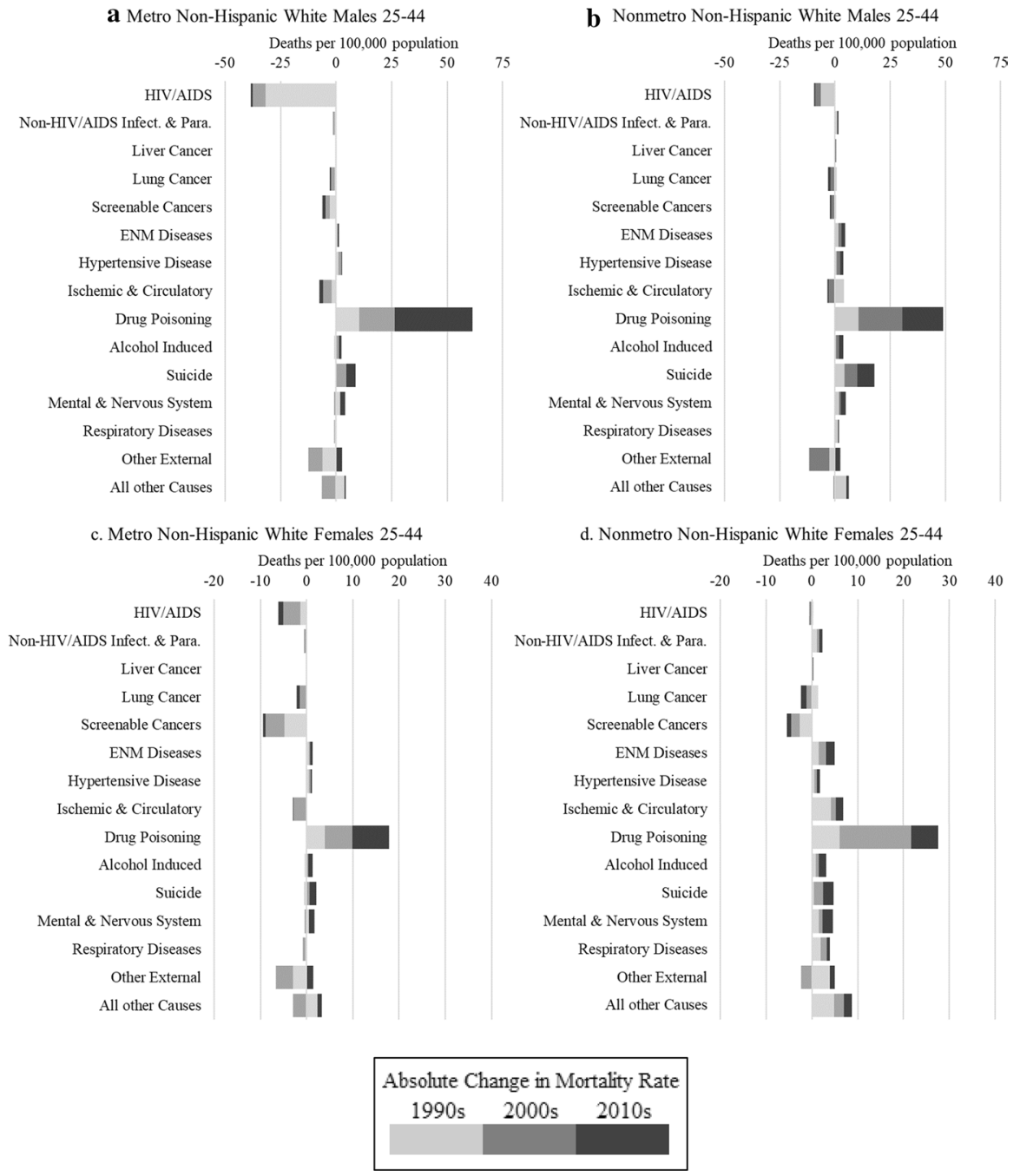

Fig. 2 Decomposition of mortality rate changes by cause of death and by decade for metro and nonmetro $\mathrm{NH}$ white males and females ages $25-44$

\section{Within-Nonmetro Differences in Mortality Trends}

\section{Divisional Differences}

Figure 4 shows nonmetro NH white mortality rates for the nine Census divisions and Appalachia from 1990 to 2018.

The first major observation is that mortality rate increases have not been uniform across the rural U.S. For ages 25-44, mortality rates increased in all divisions among females and all decisions except the Pacific for males. Rate increases (as a 


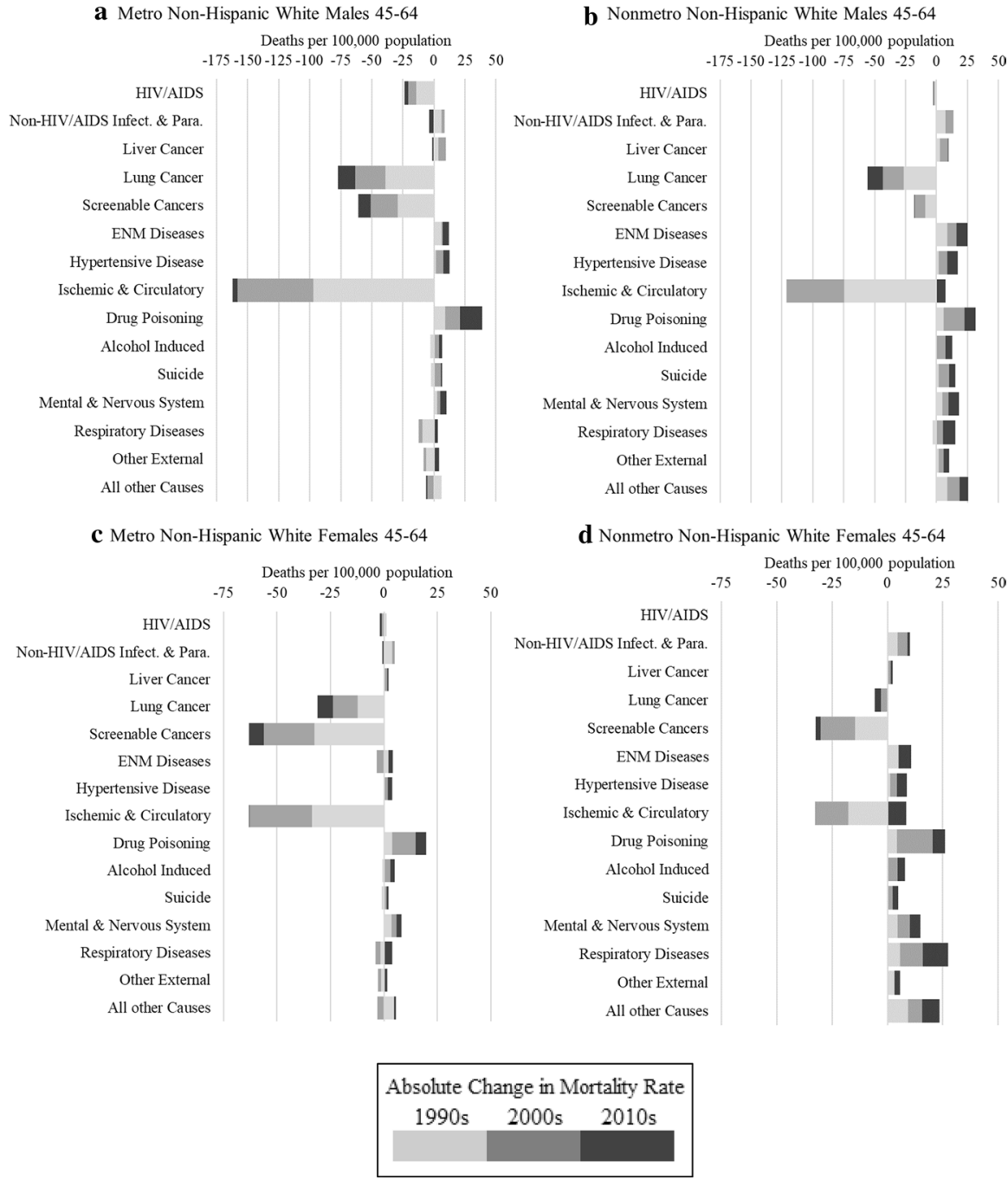

Fig. 3 Decomposition of mortality rate changes by cause of death and by decade for metro and nonmetro NH white males and females ages and 45-64

percentage) were the largest in New England, West South (WS) Central, Appalachia, and South Atlantic (for females), with Appalachia having the highest rate of all divisions in 2016-2018 for males, and East South (ES) Central having the highest rate for females. Across all divisions, rate increases were larger for females than for males. Among ages 45-64, some divisions experienced marked reductions in mortality while others experienced large increases. For males, rates increased substantially in WS Central, increased slightly in New England and ES Central, and remained comparable to 1990-1992 in Appalachia, while declining in the other six divisions. The decline was the largest in the mid-Atlantic. For females ages 45-64 

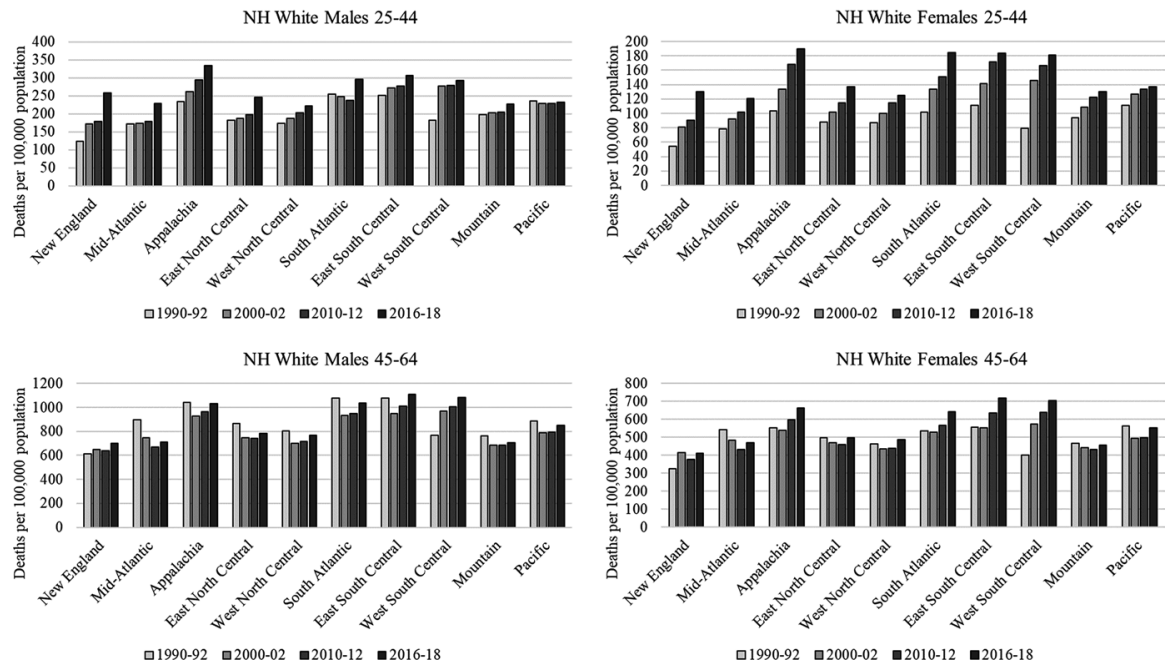

Fig. 4 All-cause mortality rates for nonmetro NH white males and females ages 25-44 and 45-64 by division. Rates are age-adjusted; Metro status is based on 2013 USDA ERS Classification

the rate declined only in the mid-Atlantic, while remaining virtually unchanged in East North (EN) Central, Mountain, and Pacific, and increasing in the other six divisions. The rate increase was the largest by far in WS Central, followed by ES Central, and New England. It is concerning that in divisions where rates had been in decline in the 1990s and 2000s, rates ticked up again in the 2010s, representing a reversal of improvements made over the prior two decades.

The second major finding is related to changes in divisional disparities in mortality rates. The gap between the highest and lowest mortality rate divisions declined for males in both age groups (see Online Appendix Tables 3.1-3.4 for mortality rates by division in 1990-1992 and 2016-2018). The standard deviation in the mortality rate also declined across the period for males ages 25-44. This gap narrowing was due to large rate increases in previously low rate divisions rather than improvements in any division. For males ages 45-64, the lowest (New England) and highest (ES Central) mortality rate divisions remained the same between 1990-1992 and 2016-2018, but the gap between those two divisions declined due to a larger increase in New England. However, the standard deviation in the mortality rate increased across the period for this group, suggesting more variation in mortality in 2016-2018 than in 1990-1992. Among females in both age groups, divisional disparities widened over the study period. Because mortality rates increased across all divisions, this gap widening was due to larger increases in some divisions than others.

Figures 5, 6, 7, and 8 decompose cause-specific changes in nonmetro NH white mortality rates by decade for each division. The actual mortality rates for 1990-1992 and 2016-2018 can be found in Online Appendix Table 3.1-3.4. Changes (in terms of both causes and magnitude of changes) were not uniform across divisions or demographic group. Some causes of death increased in some divisions while 


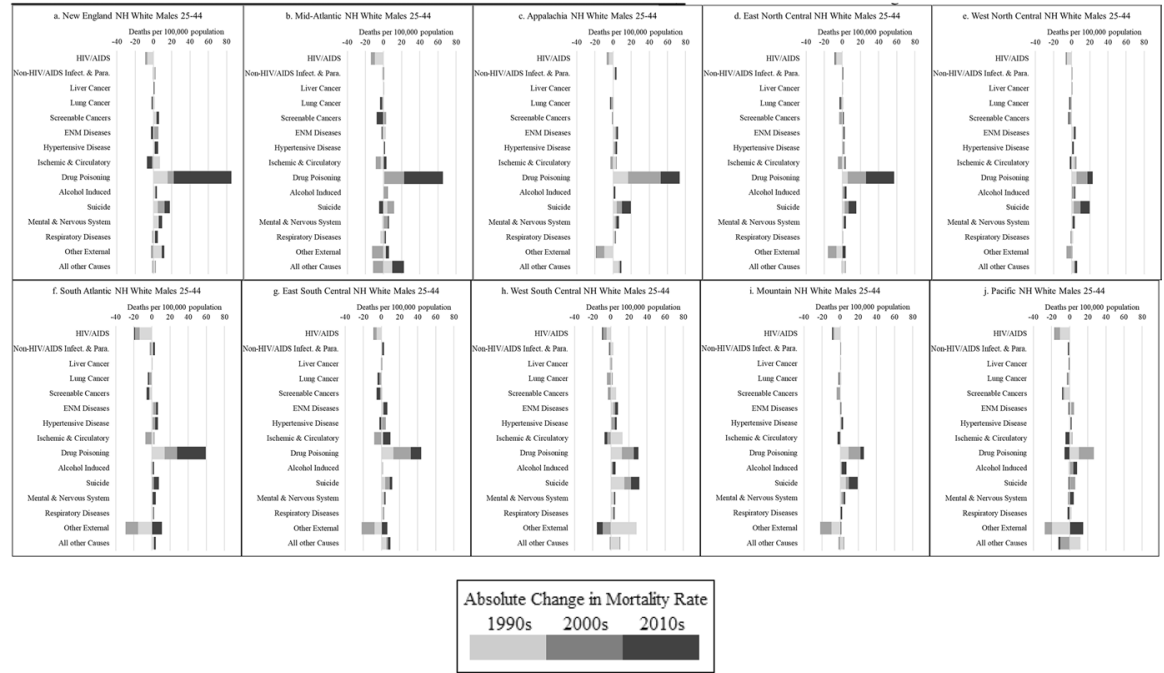

Fig. 5 Decomposition of cause-specific mortality rate changes by decade and division, nonmetro NH white males ages $25-44$

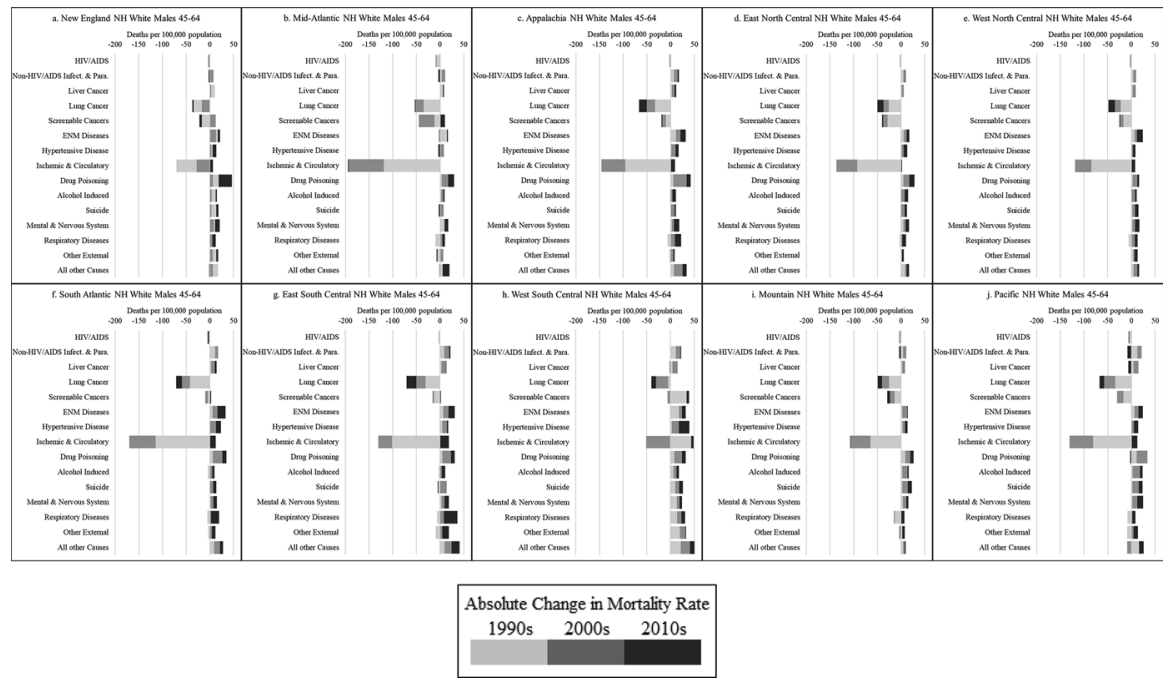

Fig. 6 Decomposition of cause-specific mortality rate changes by decade and division, nonmetro NH white males ages 45-64

declining in others, and other causes increased much more or declined much less in some divisions than others.

Males Ages 25-44 Among nonmetro NH white males ages 25-44, several causes of death increased in all ten divisions (ENM diseases, hypertensive disease, drug poisoning, alcohol-induced causes, suicide, and mental/behavioral disorders), 


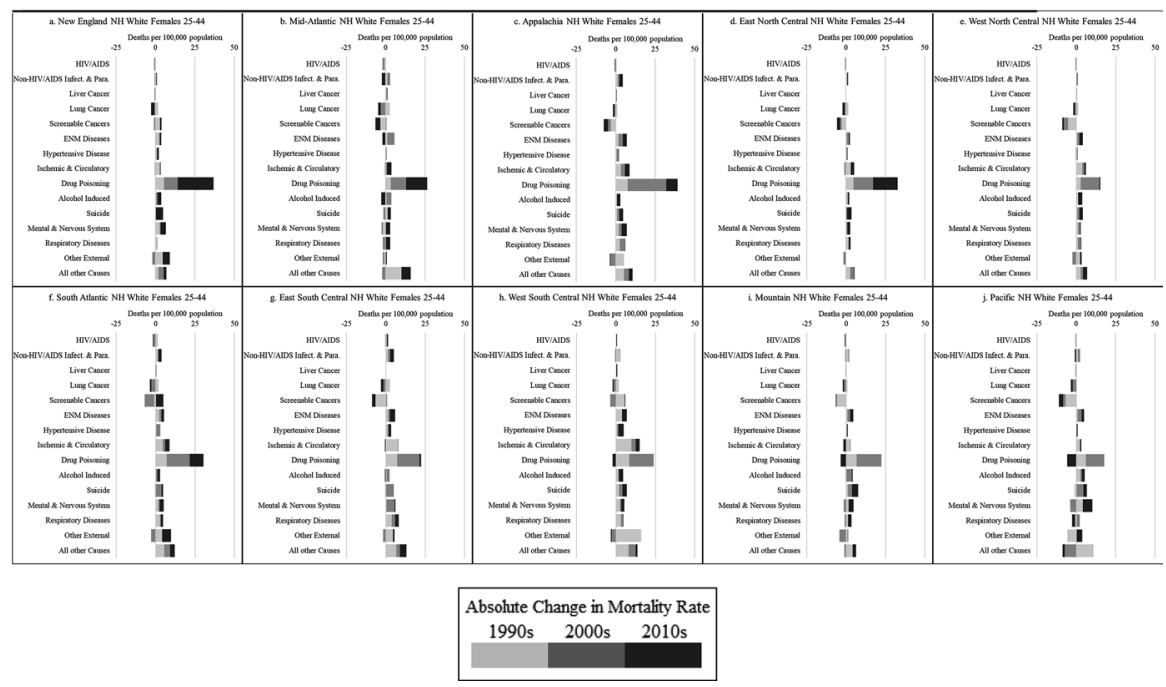

Fig. 7 Decomposition of cause-specific mortality rate changes by decade and division, nonmetro $\mathrm{NH}$ white females ages $25-44$
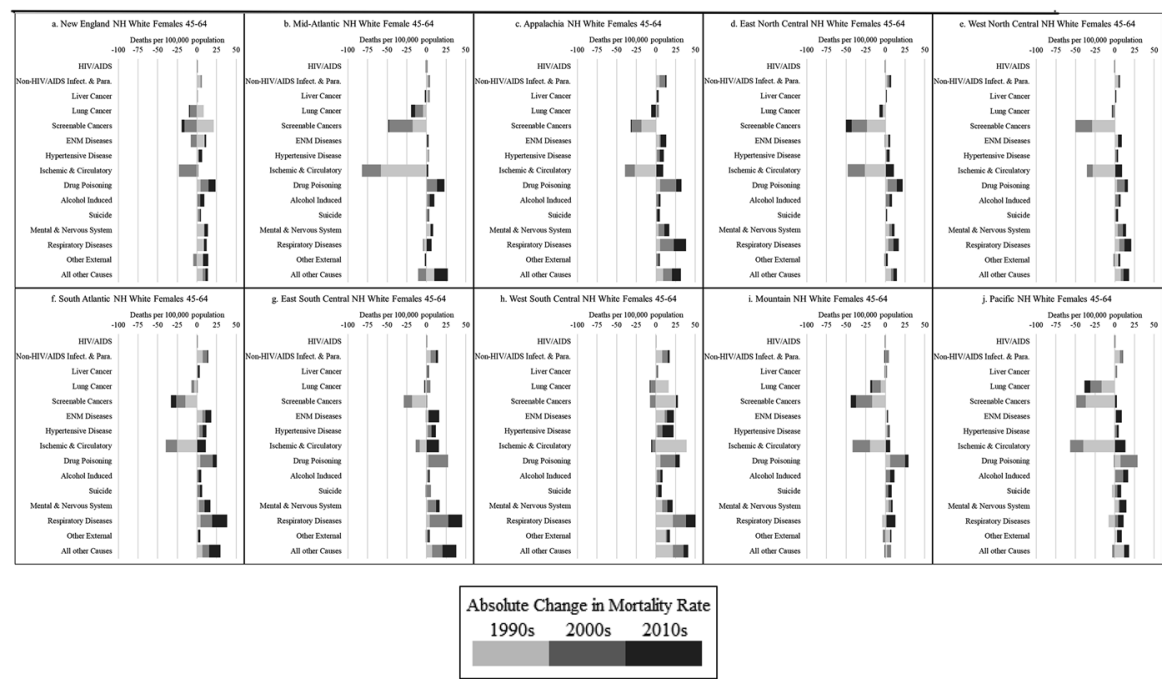

Fig. 8 Decomposition of cause-specific mortality rate changes by decade and division, nonmetro NH White females ages $45-64$

though the increases were much larger in some divisions than others. The Pacific experienced declines in the most causes of death (nine), but those declines were entirely wiped out by increases in substance and mental health-related mortality. New England, Appalachia, and WS Central are divisions of particular concern, 
given that they experienced declines in very few causes of death and comparatively large increase in most other causes over the study period.

Drug poisoning was the largest contributor to the increase in all-cause mortality in all ten divisions and was the top cause of death in 2016-2018 in New England, Mid-Atlantic, Appalachia, and EN Central. However, the magnitude and timing of the increases in drug poisoning mortality was not uniform across divisions (see Fig. 5). In New England, the Mid-Atlantic, EN Central, and South Atlantic, most of the increase occurred in the 2010s, owing to the mid-2010s surge in fentanyl availability in those regions (Monnat et al. 2019; Peters et al. In Press). Conversely, in Appalachia, the drug mortality rate increased more in the 1990s and 2000s, perhaps sparked by the increased availability of prescription opioids and then heroin in this region during this period. Other divisions (WN Central, ES Central, WS Central, Mountain, and Pacific) experienced comparatively smaller increases in drug poisoning mortality over the study period, and very small increases in drug poisoning during the 2010s. This suggests that the opioid scourge may be leveling off in those areas.

Suicide was the second or third-ranked cause of death for nonmetro males in this age group in 2016-2018 in New England, Appalachia, EN Central, WN Central, South Atlantic, WS Central, Mountain, and Pacific and was the largest contributor to the increase in mortality over the period in WS Central and the second largest contributor to the increase in all other divisions except Pacific (where it ranked third). Recent (2010s) large suicide rate increases in Appalachia, EN Central, WN Central, and Mountain divisions are alarming. Collectively, the substance abuse and mental health causes of death contributed to over $70 \%$ of the increase in all-cause mortality in all but the WS Central division, and contributed to $80 \%$ or more of the increase in New England, Mid-Atlantic, Appalachia, EN Central, Mountain, and Pacific.

Increases in the 2010s in other external causes of mortality (mostly transport accidents in select divisions: Mid-Atlantic, South Atlantic, ES Central, and Pacific) is another area for concern, considering that these causes of death had been in decline in these divisions throughout the 1990s and 2000s.

Males Ages 45-64 Several causes of death for nonmetro NH white males ages 45-64 increased across all ten divisions over the study period: non-HIV/AIDS infectious and parasitic diseases, liver cancer, EMN diseases, hypertensive heart disease, all four substance and mental health-related causes, and the all other causes category. Other external causes of death increased in nine divisions, and respiratory disease mortality increased in seven divisions. Drug poisoning was the largest driver of increases in all-cause mortality in seven divisions. Large all-cause mortality rate increases in New England, ES Central, and WS Central were driven by multiple causes rather than a single driving cause. In all three divisions, the substance abuse and mental health causes, ENM diseases, hypertensive disease, respiratory diseases, liver cancer, and the all other causes category contributed appreciably to the large all-cause mortality rate increases. Collectively, the deaths of despair contributed to over half of the increase in all-cause mortality in New England, Mid-Atlantic, Mountain, and Pacific. 
There are some good news stories. Mortality rates from ischemic/circulatory system diseases (the leading cause of death in this age group) declined in all ten divisions [though the declines varied dramatically and were the largest in Appalachia and the South Atlantic (see Fig. 6)]. Of concern is that the 1990s and 2000s declines reversed and began increasing in the 2010s in several divisions.

Females Ages 25-44 There are several areas of concerns for younger nonmetro females in multiple divisions. Mortality rates from non-HIV/AIDS infectious/ parasitic diseases, all three cardiometabolic disease causes (except ischemic in Pacific), all four substance abuse/mental health causes, respiratory diseases, and the all other causes category increased in all ten divisions. Drug poisoning was the largest contributor by far to the increase in all ten divisions and was the top cause of death in 2016-2018 in six divisions. Drug poisoning increases were largest in New England, Appalachia, EN Central, South Atlantic, and Pacific. Collectively, the deaths of despair contributed to over $50 \%$ of the increase in all-cause mortality in seven divisions.

The temporal patterns in drug poisoning increases (Fig. 7) were similar to those described for males in this age group. Mortality rates from screenable cancers increased in the 2010s in New England and the South Atlantic. Mortality rates from other external causes also increased in most divisions in the 2010s. Though these increases have generally been small, they represent a reversal of a long-term downward trend in screenable cancer and other external-cause mortality. For most divisions, the largest suicide rate increases occurred in the 2010s. Finally, given that this is an age group that has not historically suffered from high rates of cardiovascular mortalities, increases in cardiometabolic mortality rates in all divisions (with especially large increases in Appalachia, South Atlantic, ES Central, and WS Central) are alarming.

Females Ages 45-64 Among nonmetro NH white females ages 45-64, there were increases in all ten divisions in non-HIV/AIDS infectious/parasitic diseases, liver cancer, ENM diseases, hypertensive heart disease, all four substance abuse/mental health causes, respiratory diseases, other external causes (except in the MidAtlantic), and the all other causes category. The New England, ES Central, and WS Central divisions demonstrate particularly troubling mortality profiles; all causes of death increased in WS Central, all but screenable cancer increased in ES Central, and all but ischemic/circulatory system and lung cancer mortality increased in New England.

Drug poisoning was the largest contributor to the increase in all-cause mortality between 1990-1992 and 2016-2018 in five divisions, whereas respiratory diseases contributed the most to the increase in the other five divisions (see Fig. 8 and Online Appendix Table 3.4). In all ten divisions, the largest increases in drug poisoning mortality occurred in the 2000s. Alcohol-induced increases were quite large in the Mountain and Pacific divisions, representing the secondranked contributor to increasing mortality in these divisions. Collectively, deaths of despair contributed to over half of the increase in all-cause mortality in six 
divisions. Also of concern are large increases in respiratory disease mortality in several divisions. These increases started in the 1990s, but surged in the 2000s and 2010s.

There were large declines in ischemic mortality rates in all but the ES Central and WS Central, but declines were confined to the 1990s and 2000s. Ischemic mortality rates have been on the rise in the 2010s in all divisions except New England and WS Central. Declines in screenable cancer mortality rates were also mostly restricted to the 1990s and 2000s (except in a few divisions), but rates started to increase in the 2010s in Mid-Atlantic and Pacific. Declines in lung cancer mortality were quite large in the Pacific division but small in most other divisions.

\section{Economic Typology Differences}

$\mathrm{NH}$ white all-cause mortality trends by ERS county economic dependency for nonmetro counties (1989) are shown in Fig. 9. Figures 10, 11, 12, and 13 decompose the cause-specific changes by decade for each economic type. The actual mortality rates for 1990-1992 and 2016-2018 are presented in Online Appendix Tables 4.1-4.4.

In all groups, mortality rates were consistently highest in mining-dependent counties, and the mining disadvantage has grown over the past three decades. In all groups, rates were consistently lowest in farming dependent counties, which also experienced the smallest increases in mortality over the study period (except among females ages 45-64, for whom the rate increased the least in service-dependent counties). Between 1990-1992 and 2016-2018, the mortality gap between mining and farming-dependent counties increased from 70.6 to 98.9 deaths per 100,000
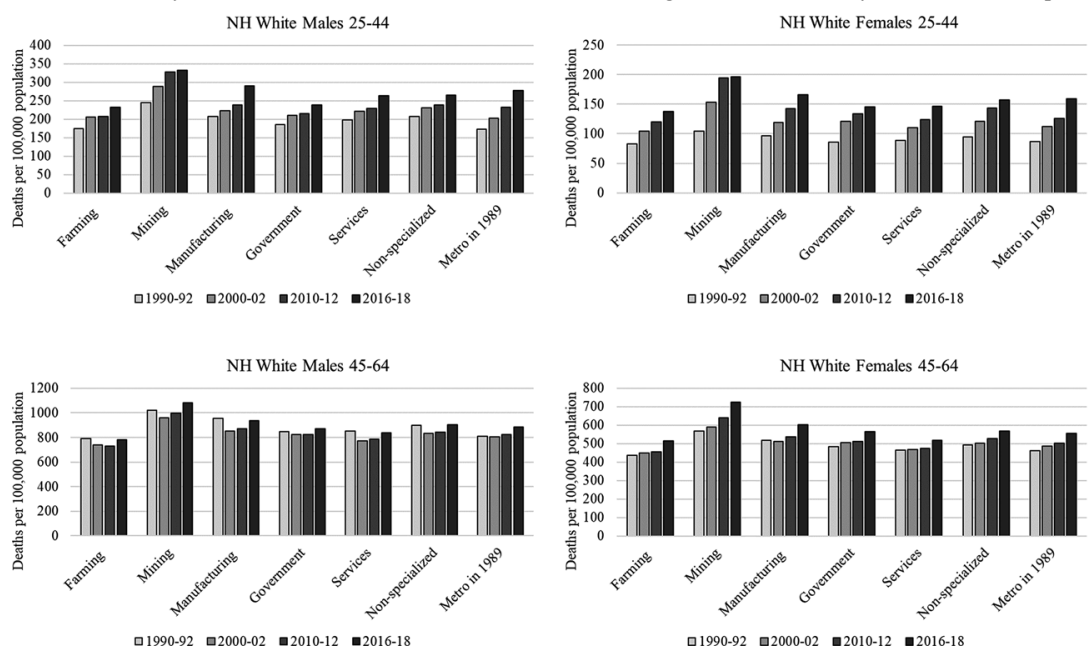

Fig. 9 All-cause mortality rates for nonmetro $\mathrm{NH}$ white males and females ages $25-44$ and $45-64$ by 1989 Economic Dependency Type. Rates are age-adjusted; $N=1947$ nonmetro counties in the coterminous U.S. Metro status are based on 2013 USDA ERS Classification; Economic dependency type is based on 1989 USDA ERS Classification; Metro in 1989=34 counties were classified as nonmetro in 2013 but metro in 1989 


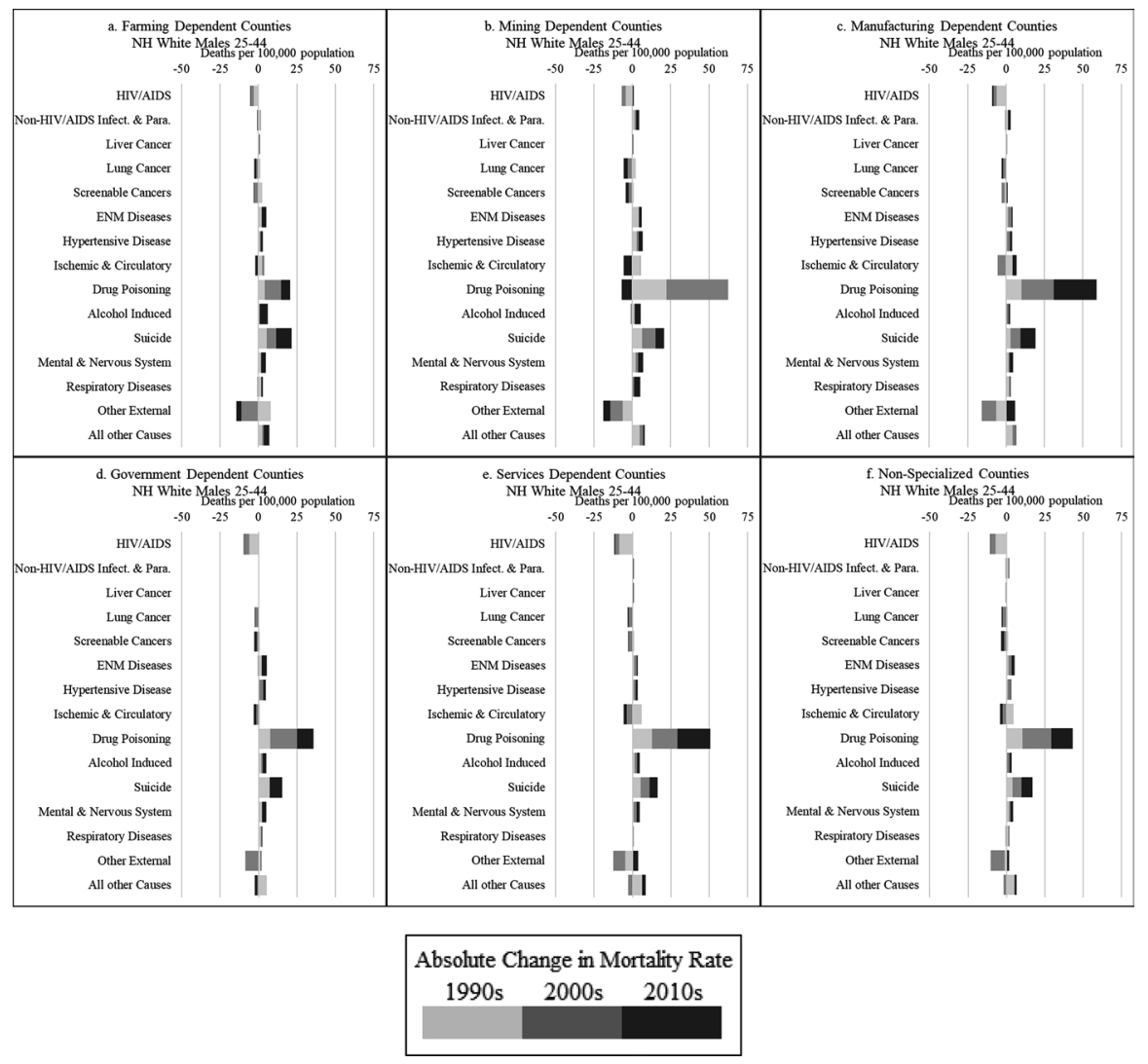

Fig. 10 Decomposition of mortality rate changes by cause of death and decade by county economic dependency, nonmetro NH white males ages 25-44

population for males ages $25-44$, from 20.1 to 59.2 for females ages $25-44$, from 229.7 to 298.1 for males ages $45-64$, and from 132.2 to 211.1 for females ages 45-64. Rates also increased substantially in the 34 counties that were metro in 1989 (when the typologies were developed) but had declined in population enough to be classified as nonmetro by 2013 . These counties had among the lowest mortality rates in 1990-1992 but among the highest in 2016-2018.

Males and Females Ages 25-44 In the younger age group, both the male and female all-cause mortality rates increased in all six economic types between 1990-1992 and 2016-2018. Mining-dependent counties experienced the largest increases in six causes of death among males (non-HIV/AIDS infectious/parasitic diseases, ENM diseases, hypertensive heart disease, mental/behavioral disorders, respiratory diseases, and the all other causes category) and eight causes of death among females (nonHIV/AIDS infectious/parasitic diseases, ENM diseases, hypertensive heart disease, ischemic/circulatory system diseases, drug poisoning, mental/behavioral disorders, 


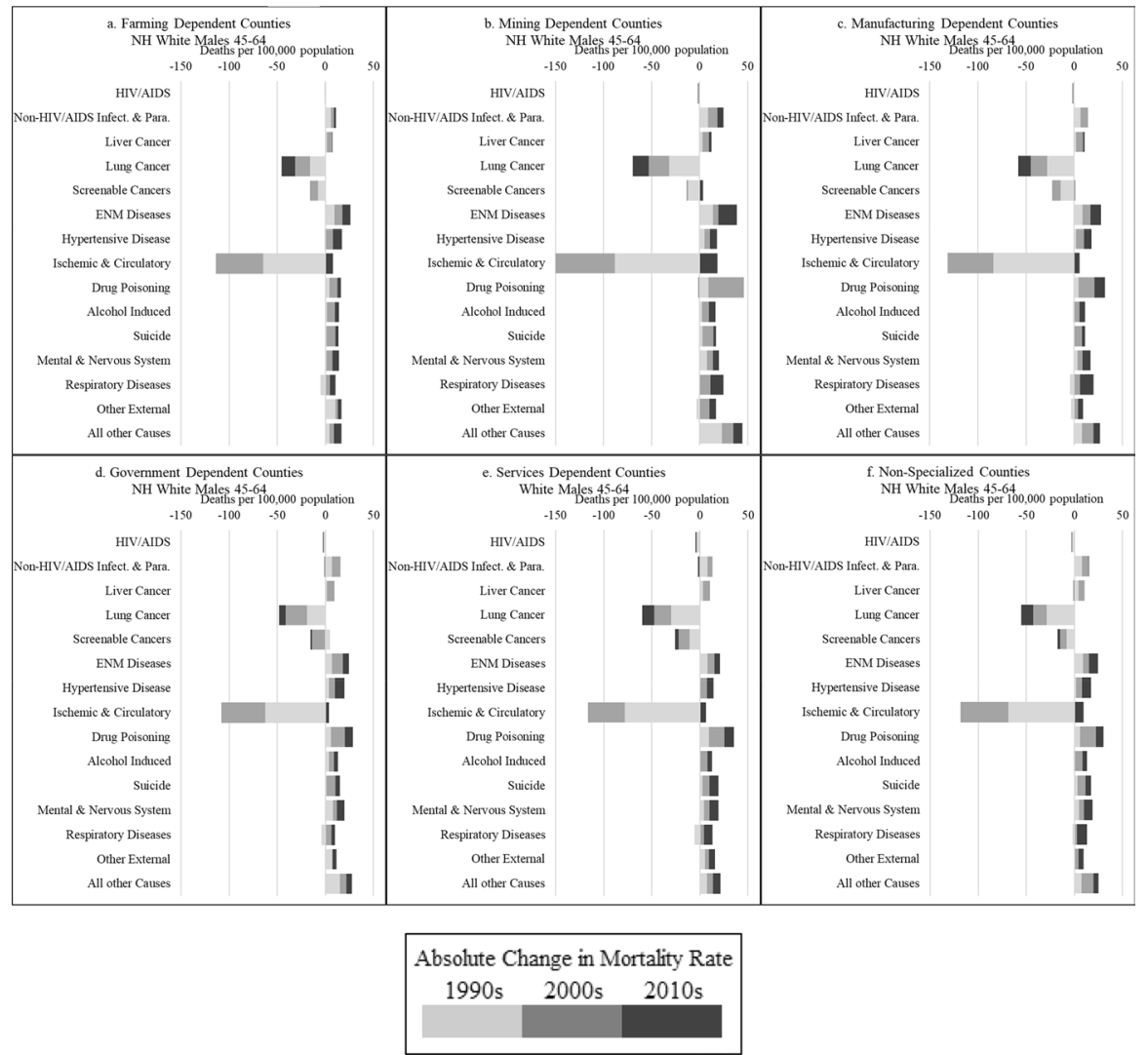

Fig. 11 Decomposition of mortality rate changes by cause of death and decade by county economic dependency, nonmetro NH white males ages 45-64

respiratory diseases, and the all other causes category). Suicide rates increased the most in farming-dependent counties for both males and females. Farming-dependent counties also had the largest increase in the male alcohol-induced mortality rate. The largest increase in male drug poisoning mortality was in manufacturing counties, which experienced a surge in the 2010s. Most of the increase in drug poisoning mortality in the other economic types occurred during the 1990s and 2000s. Mining counties were the only category to experience a decline in drug poisoning mortality in the 2010s (see Figs. 10 and 12). This is an area for optimism, but the picture is not all rosy; alcohol, suicide, and mental/behavioral deaths (which are mostly drugs and alcohol-related) increased during this period.

Males and Females Ages 45-64 In the older age group, female all-cause mortality rates increased in all six economic types. However, male all-cause mortality rates increased in mining, government, and nonspecialized counties but decreased in farming, manufacturing, and service counties. Mining counties experienced the 


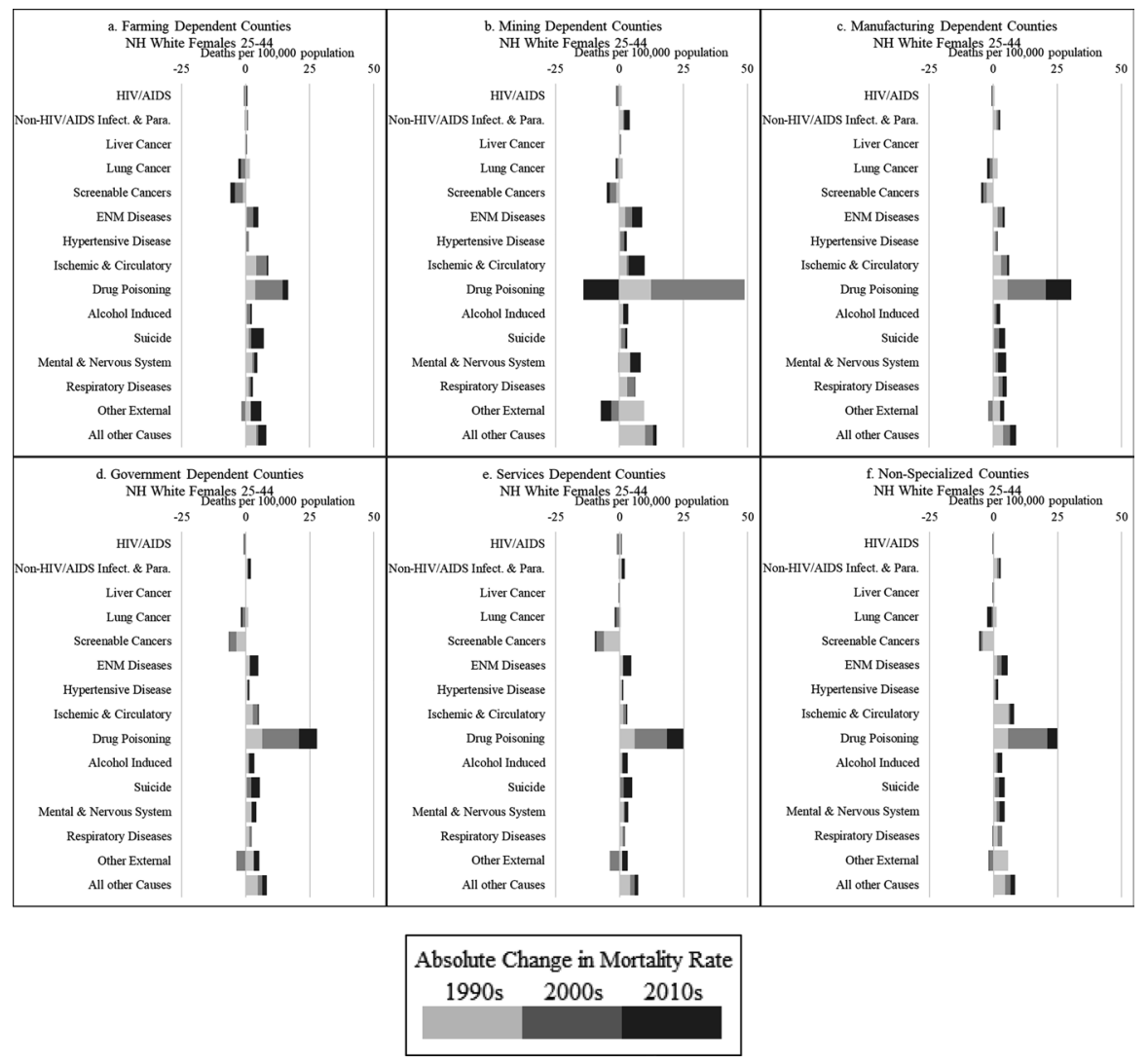

Fig. 12 Decomposition of mortality rate changes by cause of death and decade by county economic dependency, nonmetro $\mathrm{NH}$ white females ages $25-44$

largest increase in eight causes of death among males (non-HIV/AIDS infectious/ parasitic diseases, liver cancer, ENM diseases, drug poisoning, alcohol-induced causes, mental/behavioral disorders, respiratory diseases, and the all other causes category) and eight causes of death among females (non-HIV/AIDS infectious/ parasitic diseases, ENM diseases, hypertensive heart disease, drug poisoning, mental/behavioral disorders, respiratory diseases, other external causes, and the all other causes category). Males and females in all economic types experienced declines in both lung and screenable cancer mortality. Ischemic/circulatory mortality also declined in all six economic types over the 30-year period, but there were upticks in rates in the 2010s in all six types, with especially large and concerning increases in mining counties. Finally, there were relatively large increases in respiratory disease mortality rates in the 2010s in all six economic types, but increases were the largest in mining and manufacturing counties. 


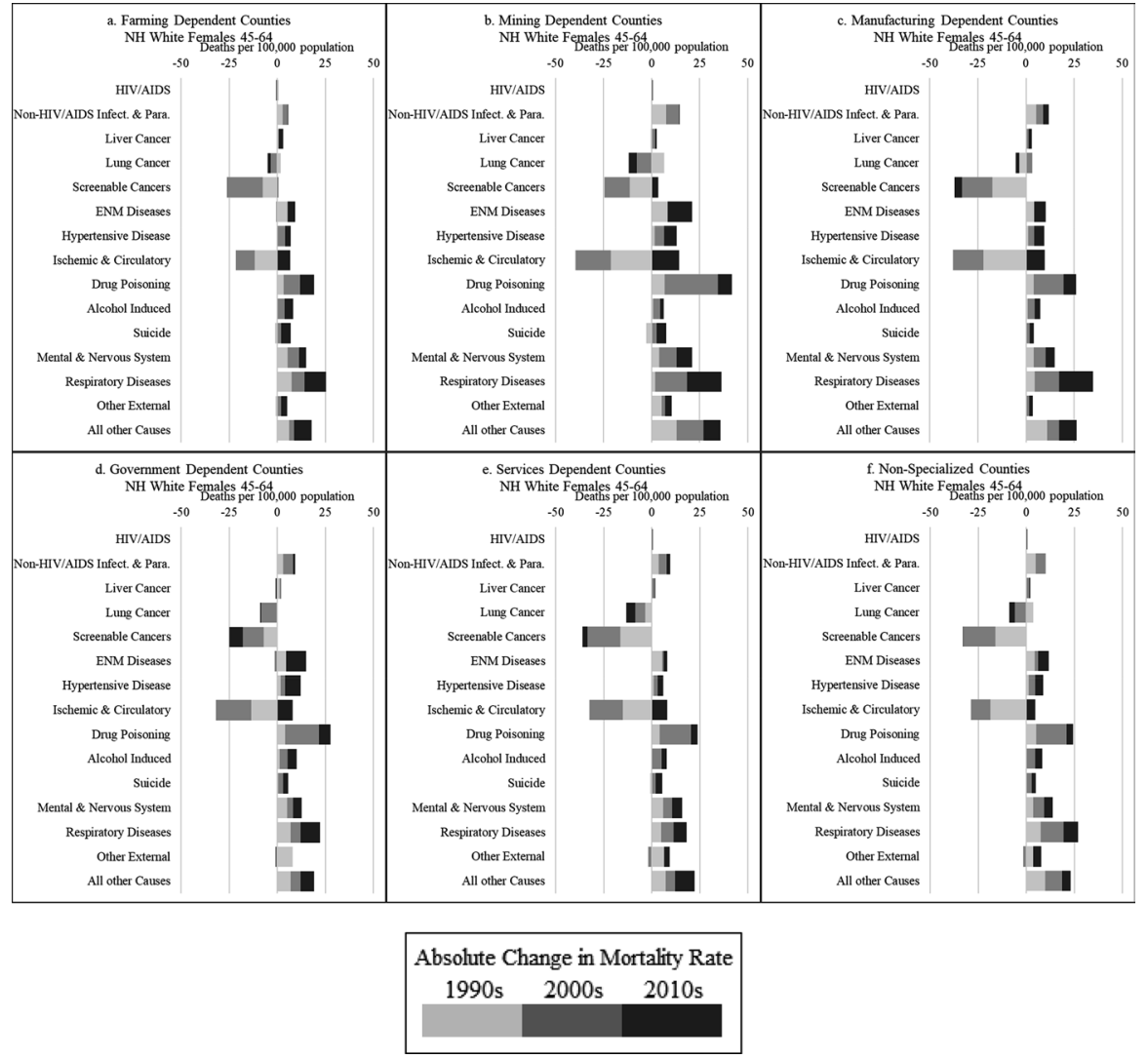

Fig. 13 Decomposition of mortality rate changes by cause of death and decade by county economic dependency, nonmetro NH white females ages 45-64

\section{Discussion}

Numerous articles on the increasing rural mortality penalty note that it is not due to increases in rural mortality but instead to larger mortality declines in urban than in rural areas. For example, based on trends observed from 1968 to 2007, James (2014) suggested that "research should target the slow rate of improvement in mortality in the rural United States" (p. 11). A decade later, we see that this slow rate of improvement in rural America turned into (in some places rapid) rural mortality rate increases.

There are several other important takeaways from this research. First, the nonmetro working-age mortality penalty is wide and growing. This is the case for the nonmetro population overall (all racial/ethnic groups combined) and for $\mathrm{NH}$ whites specifically. The increasing gap is due to a combination of metro mortality rate declines that occurred primarily throughout the 1990s and 2000s and 
nonmetro mortality rate increases that occurred primarily throughout the 2010s. The gap has also grown for NH blacks and Hispanics, but an analysis of trends for those groups was beyond the scope of this paper given their much different mortality profiles.

Second, the nonmetro mortality penalty is not limited to one or two specific causes of death but is pervasive across multiple disease and injury categories, suggesting that more than one underlying structural cause is to blame. Over the past 30 years, nonmetro working-age $\mathrm{NH}$ whites experienced increases in more causes of death and by a greater magnitude than their metro peers. Among older working-age NH white males, smaller declines in lung and screenable cancers, ischemic/ circulatory system diseases, and HIV/AIDS, and increases in diseases of the respiratory system, metabolic diseases, and external causes contributed to the growing nonmetro mortality penalty. Among older working-age females, much smaller declines in lung and screenable cancers and ischemic/circulatory diseases and larger increases in respiratory disease mortality accounted for nearly $70 \%$ of the growth in the nonmetro gap. Among younger working-age males, smaller reductions in ischemic/circulatory disease mortality and HIV/AIDS (which declined dramatically in metro areas but was already comparatively low in nonmetro areas), and larger increases in suicide contributed most to the growing nonmetro disadvantage. Among younger working-age females, increases in ischemic/circulatory system diseases, metabolic diseases, and external causes were the largest contributors to the growing nonmetro mortality disadvantage. The surge in drug poisoning mortality rates is a major population health crisis in metro and nonmetro counties, alike. Indeed, among nonmetro young adults, increases from drug poisoning more than wiped-out mortality declines in other causes of death over the past three decades. The increases in mortality from cardiovascular causes among nonmetro young adults are consistent with recent research from Lawrence et al. (2017) showing worse cardiovascular health (due to rising obesity) in this group. Given that heart disease should not be affecting this age group, this is a troubling trend. As noted by Elo et al. (2019), adverse conditions from obesity and substance abuse have life course implications. We are likely to see continued increases in obesity- and substance abuse-related mortality in this cohort as they age.

Third, drug poisoning, alcohol-induced causes, suicide, and mental/behavioral disorders (the deaths of despair) have elicited significant media and academic attention over the past several years. All four causes of death increased among both metro and nonmetro NH white males and females in both age groups (some quite dramatically). Collectively, they represent a major contributor to NH white allcause mortality rates and to the past three-decade growth in mortality in both metro and nonmetro counties. However, with the exception of suicide among males ages 25-44, these causes did not substantially contribute to the widening nonmetro mortality penalty because mortality rate increases from drug poisonings were larger in metro areas and increases from suicide, alcohol, and mental and behavioral disorders were only slightly higher in nonmetro areas. It should be noted that drug and alcohol deaths are most certainly under-captured when only considering the specific drug and alcohol underlying cause of death codes. Glei and Preston (2020) estimate that drug use is associated with more than twice the number of drug deaths than 
are captured with the specific ICD drug poisoning codes. Some unmeasured portion of the infectious disease mortality rate (which is driven by viral hepatitis) are from injection drug use, some share of liver cancer deaths are from chronic heavy alcohol use and injection drug-related hepatitis, nearly all deaths in the mental/ behavioral disease category are attributable to drugs or alcohol, and some share of 'other' external causes of death are from drug/alcohol-related traffic accidents. Each of these other causes of death increased more among nonmetro males and females than among their metro peers.

Fourth, for most causes of death that declined over the past 30 years, most of the decline occurred in the 1990s or 2000s. The 2010s has been a troubling decade, ushering in reversals in some causes that were previously in decline (ischemic/circulatory system diseases, external causes) and more rapid increases in other causes of death which were already increasing in the 1990s and 2000s (drug poisoning, suicide, mental/behavioral disorders, metabolic diseases, hypertensive heart disease). The timing of mortality rate increases is instructive for identifying potential upstream causes. For example, the bulk of the increase in nonmetro drug poisonings occurred in the 1990s and 2000s (due mostly to prescription opioids followed by heroin), whereas metro rates surged in the 2010s (due first to heroin and then the introduction of fentanyl into the drug supply) (Peters et al. In Press). Most of the nonmetro suicide and alcohol mortality rate increases occurred in the $2000 \mathrm{~s}$ and 2010s, suggesting a potential Great Recession effect, but the suicide rate was increasing among age 25-44 nonmetro males in the 1990s suggesting a much longer-term problem than the Great Recession. Increases in metabolic and hypertensive diseases both started in the 1990s, representing a long-term phenomenon that may be explained by the increasing obesogenic environment (Masters et al. 2018).

Fifth, there are large divisional disparities in nonmetro mortality trends, which are narrowing for males but increasing for females. The narrowing gap for males was due to large increases in previously low-rate divisions (e.g., New England) rather than improvements in rates for any divisions, and the increasing disparity for females was due to larger increases in some divisions than others. Absolute mortality levels and trends are worst in the ES Central, WS Central, Appalachia, and South Atlantic divisions. New England also exhibits upward trends, though absolute rates remain comparatively lower than many other divisions. These divisional trends were driven by multiple causes of death, including the deaths of despair, cardiometabolic diseases, respiratory disease, and liver cancer. The southern mortality penalty is consistent with recent research showing a persistent and growing mortality penalty for this region (James 2014; James and Cossman 2017; James et al. 2018). Together, these findings suggest that the rural southern and Appalachian disadvantage may be generational and impervious to changes in population composition over time. However, not all of rural America is in dire straits. Mortality rates declined dramatically among males and females ages 45-64 in the mid-Atlantic and among males ages 45-64 in the EN Central and Mountain divisions.

Sixth, mining-dependent counties have diverged from the other economic dependency types since the mid-2000s. The intersection between Appalachia and mining dependence is important, but mining-dependent counties are not restricted to Appalachia. Mining counties experienced larger increases than the other economic 
types in multiple causes of death over the study period, particularly drug poisonings, mental/behavioral disorders, infectious diseases, cardiometabolic diseases, and respiratory diseases. Moreover, despite large improvements in cancers and ischemic/ circulatory diseases in mining counties, rates in mining counties remain the highest of all economic types. Farming counties have a comparative mortality advantage, due in large part to much smaller increases in drug poisoning and infectious disease mortality than the other economic types. However, large increases in suicide and alcohol-induced mortality in farming-dependent counties are concerning, as they risk driving up all-cause mortality in these counties. Other notable areas for concern include large increases in drug poisoning and respiratory disease mortality in manufacturing counties and a large increase in suicide mortality among males ages 45-64 in service counties.

Finally, there is an important gender story that has been lost in the frenzy surrounding rising midlife mortality. Mortality increases among nonmetro females have been startling. The mortality growth among nonmetro females was much larger than among nonmetro males. Among younger females, increases were pervasive across all divisions, all economic dependency categories, and multiple causes of death. Given that these women are still very young, these trends forebode troubling outcomes in the decades to come. Young adult nonmetro male mortality rates also increased in all but the Pacific, but the rate increases were much larger in every division for females. Moreover, nonmetro males ages 45-64 experienced declines in mortality in all but four divisions, whereas females in this age group experienced a decline only in the Mid-Atlantic. Whereas divisional disparities are declining among males, they are widening among females, with nonmetro females experiencing increasingly concentrated disadvantage in Appalachia and the South. At the national level, others have observed this troubling trend (Elo et al. 2019; Woolf and Schoomaker 2019) that appears to be driven by the widening educational gap in mortality (Montez and Zajacova 2013a, b, 2014; Sasson 2016). Yet, it has received little media or political attention.

Increasing mortality rates across multiple causes suggest that there is not one underlying explanation. Instead, systemic failures across a variety of institutions and policies have likely contributed to rural America's troubling mortality trends generally and widening within-rural disparities more specifically. As we are seeing with the nation's current COVID-19 pandemic, a nation's health care infrastructure has a major influence on certain causes of death, including HIV/AIDS and screenable cancers. Thanks to public health efforts, the U.S. has made great inroads in these areas. Mortality differences in these causes may reflect geographic disparities in health care access. However, differences in respiratory disease, lung cancer, drug poisoning, and cardiometabolic diseases reflect behavioral factors-smoking, obesity, and substance use. Of course, both health care and behavioral factors are influenced by economic and social disadvantage, which also increase exposure to several other types of health-harming environments and increase risk of multiple causes of death. Geographically variant policy choices also matter. For example, although smoking is a behavioral risk factor for several diseases, agentic explanations are unsatisfactory if we consider that geographic trends in smoking mortality are related 
to different state-level policy choices on tobacco control, including excise taxes and restricting smoking in public places.

So how should we address the troubling trends observed in these analyses? Behavioral interventions targeting smoking, diet, and exercise have been widely advocated in the literature and have been attempted for decades, but they appear to have had little impact on reducing rural-urban or within-rural disparities. In fact, based on fundamental cause theory (Link and Phelan 1995), it is possible that such interventions have exacerbated disparities if they have been more effective in geographic areas with the most educated and otherwise well-resourced populations (Montez et al. 2019). Another oft-cited strategy for reducing rural mortality rates is to increase access to health care. To be sure, improved health care access (and quality) has the potential to reduce disparities in some types of mortality that are amenable to screening and known-effective treatments, but health care does not keep people from getting sick in the first place. Far too often, the public health approach has been to apply post hoc-targeted health care and behavioral intervention to places with the worst health profiles. This approach has been costly and ineffective because it treats problems after they arise rather than preventing their onset. Instead, the more cost effective and humane approach would be to apply upstream interventions that target the structural (economic, social, environmental), corporate, and policy determinants of health to prevent future generations from exacerbating these already problematic mortality trends. Growing rural-urban and within-rural disparities may reflect increasing inequities in any number of upstream social-structural factors, including educational attainment, which is becoming an increasingly important determinant of morality disparities (Hayward et al. 2015); as well as material resources, opportunities for employment and upward mobility, social capital and integration (Yang et al. 2011); housing quality, environmental quality, and the distribution of economic, educational, and/or social resources. In a study that covered 2004-2012, Long et al. (2018) found that median income and percent poverty explained nearly all of the rural mortality disadvantage and argued that interventions targeting social determinants of health in rural areas must be prioritized. Importantly, all of these factors are influenced by politics and policy decisions at the national, state, and local levels. Future research to understand which of these upstream factors has contributed the most to widening geographic disparities in various types of mortality and which policies may be driving these upstream trends (i.e., the causes of the causes of the causes) will be key to identifying specific macro-level interventions for reducing rural health disparities and improving rural population health generally.

\section{Limitations}

Results should be considered in light of some limitations. First, this study focused on NH whites. Rural racial/ethnic minorities have considerably higher mortality rates than whites, but mortality rates have improved more among blacks and Hispanics than among whites over the past 30 years (National Academy of Sciences forthcoming). Future research should examine whether the cause-specific mortality trends observed for nonmetro NH whites vary from those for other nonmetro racial/ 
ethnic groups and how these trends have affected racial/ethnic disparities in mortality rates in nonmetro areas.

Second, these analyses did not adjust for compositional differences. The observed trends may be partly explained by compositional (e.g., educational attainment, poverty) differences across different nonmetro divisions and labor market type. Rural population composition has shifted over the past 30 years (Burton et al. 2013; Lichter and Brown 2011). However, health outcomes persist in communities over multiple generations (James et al. 2018). Cosby et al. (2019) show that the rural mortality penalty is not the result of place-based differences in education, income, and poverty. Together, these findings suggest that the differences in mortality rate changes observed in this study are likely not attributable to compositional changes. Instead, contextual characteristics of places are salient to understanding these changes.

Third, there are multiple ways to dissect rural America. I attempted only two-division and economic type. The RUCCs have been used extensively in other research. Other important differences may be revealed by disaggregating by measures of economic change, population change, cultural history, and political orientation.

\section{Conclusion}

Nonmetro mortality rates are increasingly diverging from those in metro areas. The growing nonmetro mortality penalty is due both to declines in metro mortality and increases in nonmetro mortality. No single cause of death is to blame; smaller nonmetro declines in cancers and ischemic/circulatory system diseases and larger increases in suicide, alcohol-induced cause, mental/behavioral disorders, cardiometabolic diseases, infectious diseases, and respiratory diseases are major culprits. Mortality rate trends have been particularly problematic for females. However, not all of rural America is in dire straits. While there is much to be concerned about in Appalachia, the South, and increasingly New England, some groups have seen improvement in the Mid-Atlantic, EN Central, and Mountain divisions. My analysis of specific causes of death begins to offer insight into what's driving these disparities, but research is needed that identifies the specific upstream causal explanations for these trends, particularly those that are amenable to policy change.

Finally, there has been significant media, political, and scholarly attention to increases in drug, alcohol, and suicide mortality. To be sure, increases in these causes over the past three decades have been alarming. But an unfortunate side effect of our nation's focus on deaths of despair is that notable increases in other important causes have remained under the radar. This includes obesity-related causes (metabolic and hypertensive diseases) and diseases of the respiratory system. In the frenzy to understand what is causing the increase in deaths of despair, we should not lose sight of these other (sometimes more) important contributors to working-age adult mortality, as they too reflect underlying systemic failures that have affected some places more than others. 
Acknowledgements The author acknowledges support from two research networks funded by the National Institute on Aging (R24 AG065159 and 2R24 AG045061), research funding from the United States Department of Agriculture, National Institute of Food and Agriculture Grant Award \#201868006-27640, support from the Population Research Institute at Penn State (which receives core funding from the Eunice Kennedy Shriver National Institute of Child Health and Human Development (P2CHD041025), and support from the USDA Agricultural Experiment Station Multistate Research Project: W4001, Social, Economic, and Environmental Causes and Consequences of Demographic Change in Rural America

\section{References}

Adamy, J., \& Overberg, P. (2017). Rural America is the New 'Inner City'. Wall Street Journal, May 26, 2017. Retrieved November 18, 2018, from https://www.wsj.com/articles/rural-america-is-the-newinner-city-1495817008.

Bailey, C., Jensen, L., \& Ransom, E. (Eds.). (2010s). Rural America in a globalizing world: Problems and prospects for the 2010s. Morgantown, WV: West Virginia University Press.

Brown, D. L., \& Schafft, K. A. (2011). Rural people \& communities in the 21st century: Resilience \& transformation. Malden, MA: Polity.

Brown, D. L., \& Swanson, L. E. (2003). Challenges for rural America in the twenty-first century. University Park, PA: Pennsylvania State University Press.

Burton, L. M., Lichter, D. T., Baker, R. S., \& Eason, J. M. (2013). Inequality, family processes, and health in the "New" Rural America. American Behavioral Scientist, 57(8), 1128-1151.

Case, A., \& Deaton, A. (2015). Rising morbidity and mortality in midlife among white non-Hispanic Americans in the 21st century. Proceedings of the National Academy of Sciences, 112(49), 15078-15083.

Case, A., \& Deaton, A. (2017). Mortality and morbidity in the 21st century. Brookings Papers on Economic Activity Spring.

Cosby, A. G., McDoom-Echebiri, M. M., James, W., Khandekar, H., Brown, W., \& Hanna, H. L. (2019). Growth and Persistence Of Place-Based Mortality in the United States: The rural mortality penalty. American Journal of Public Health, 109(1), 155-162.

Cosby, A. G., Neaves, T. T., Cossman, R. E., Cossman, J. S., James, W. L., Feierabend, N., et al. (2008). Preliminary evidence for an emerging nonmetropolitan mortality penalty in the United States. American Journal of Public Health, 98(8), 1470-1472.

Elo, I. T., Hendi, A. S., Ho, J. Y., Vierboom, Y. C., \& Preston, S. H. (2019). Trends in non-hispanic white mortality in the United States by Metropolitan-Nonmetropolitan Status and Region, 1990-2016. Population and Development Review, 45(3), 549-583.

Garcia, M. C., Faul, M., Massetti, G., Thomas, C. C., Hong, Y., Bauer, U. E., et al. (2017). Reducing potentially excess deaths from the five leading causes of death in the rural United States. Morbidity and Mortality Weekly Report, 66(2), 1-7.

Glei, D. A., \& Preston, S. H. (2020). Estimating the impact of drug use on US mortality, 1999-2016. PLOS ONE, 15(1), e0226732.

Hayward, M. D., Hummer, R. A., \& Sasson, I. (2015). Trends and group differences in the association between educational attainment and U.S. adult mortality: Implications for understanding education's causal influence. Social Science \& Medicine, 127, 8-18.

Ho, J. Y. (2013). Mortality under age 50 accounts for much of the fact that US life expectancy lags that of other high-income countries. Health Affairs, 32(3), 459-467.

James, W., Cossman, J., \& Wolf, J. (2018). Persistence of death in the United States: The remarkably different mortality patterns between America's Heartland and Dixieland. Demographic Research, 39(33), 897-910.

James, W., \& Cossman, J. S. (2017). Long-term trends in Black and White mortality in the rural United States: Evidence of a race-specific rural mortality penalty. Journal of Rural Health, 33(1), 21-31.

James, W. L. (2014). All rural places are not created equal: Revisiting the rural mortality penalty in the United States. American Journal of Public Health, 104(11), 2122-2129.

Jensen, L., Tickamyer, A. R., \& Slack, T. (2019). Rural-urban variation in informal work activities in the United States. Journal of Rural Studies, 68, 276-284. 
Kegler, S. R., Stone, D. M., \& Holland, K. M. (2017). Trends in suicide by level of urbanization-United States, 1999-2015. Morbidity and Mortality Weekly Report, 66, 270-273.

Lawrence, E., Hummer, R. A., \& Harris, K. M. (2017). The Cardiovascular Health of Young Adults: Disparities along the Urban-Rural Continuum. The Annals of the American Academy of Political and Social Science, 672(1), 257-281.

Lichter, D. T., \& Brown, D. L. (2011). Rural America in an urban society: Changing spatial and social boundaries. Annual Review of Sociology, 37(1), 565-592.

Lichter, D. T., \& Schafft, K. (2016). People and places left behind: rural poverty in the new century. In D. Burton \& L. M. Brady (Eds.), The oxford handbook of the social science of poverty (pp. 317-340). Oxford: Oxford University Press.

Link, B. G., \& Phelan, J. (1995). Social conditions as fundamental causes of disease. Journal of Health and Social Behavior 80-94.

Lobao, L. (2010s). Economic Change, Structural Forces, And Rural America: Shifting Fortunes Across Communities. In C. Bailey, L. Jensen, \& E. Ransom (Eds.), Rural America in a globalizing world: Problems and prospects for the 2010s (pp. 543-555). Morgantown, WV: West Virginia University Press.

Long, A. S., Hanlon, A. L., \& Pellegrin, K. L. (2018). Socioeconomic variables explain rural disparities in US mortality rates: Implications for rural health research and policy. SSM - Population Health, 6 , $72-74$.

Masters, R. K., Tilstra, A. M., \& Simon, D. H. (2018). Explaining recent mortality trends among younger and middle-aged white Americans. International Journal of Epidemiology, 47(1), 81-88.

Monnat, S. M. (2019). The contributions of socioeconomic and opioid supply factors to U.S. drug mortality rates: Urban-rural and within-rural differences. Journal of Rural Studies, 68, 319-335.

Monnat, S. M., \& Brown, D. L. (2017). More than a rural revolt: Landscapes of despair and the 2016 presidential election. Journal of Rural Studies, 55, 227-236.

Monnat, S. M., Peters, D. J., Berg, M. T., \& Hochstetler, A. (2019). Using census data to understand county-level differences in overall drug mortality and opioid-related mortality by opioid type. American Journal of Public Health, 109(8), 1084-1091.

Montez, J. K., Hayward, M. D., \& Zajacova, A. (2019). Educational disparities in adult health: US States as Institutional Actors on the Association. Socius, 5, 2378023119835345.

Montez, J. K., \& Zajacova, A. (2013a). Explaining the widening education gap in mortality among U.S. white women. Journal of Health and Social Behavior, 54(2), 166-182.

Montez, J. K., \& Zajacova, A. (2013b). Trends in mortality risk by education level and cause of death among US white women From 1986 to 2006. American Journal of Public Health, 103(3), 473-479.

Montez, J. K., \& Zajacova, A. (2014). Why is life expectancy declining among low-educated women in the United States? American Journal of Public Health, 104(10), e5-e7.

Murray, C. J. L., Kulkarni, S. C., Michaud, C., Tomijima, N., Bulzacchelli, M. T., Iandiorio, T. J., et al. (2006). Eight Americas: Investigating mortality disparities across races, counties, and race-counties in the United States. PLoS Medicine, 3(9), e260.

National Academy of Sciences Committee on Rising Midlife Mortality. (Forthcoming 2020). Rising Midlife Mortality Rates and Socioeconomic Disparities.

National Center for Health Statistics. (2019). National Health Interview Survey Tables of Summary Health Statistics. Retrieved January 23, 2020 via https://www.cdc.gov/nchs/nhis/shs/tables.htm.

National Center for Health Statistics (NCHS). (2020). Detailed Mortality Files, 1990-2018. Accessed under a restricted data use agreement.

Carr, P. J., \& Kefalas, M. (2009). Hollowing out the middle: the rural brain drain and what it means for America. Boston, MA: Beacon Press.

Peters, D. J. (2013). American income inequality across economic and geographic space, 1970-2010. Social Science Research, 42(6), 1490-1504.

Peters, D. J., Monnat, S. M., Hochstetler, A. L., \& Berg, M. T. (In Press).The opioid hydra: Understanding overdose mortality epidemics and syndemics across the rural-urban continuum. Rural Sociology.

Rigg, K. K., Monnat, S. M., \& Chavez, M. N. (2018). Opioid-related mortality in rural America: Geographic heterogeneity and intervention strategies. International Journal of Drug Policy, 57, $119-129$.

Sasson, I. (2016). Trends in life expectancy and lifespan variation by educational attainment: United States, 1990-2010. Demography, 53(2), 269-293.

Singh, G. K., \& Siahpush, M. (2014). Widening rural-urban disparities in life expectancy, U.S., 19692009. American Journal of Preventive Medicine, 46(2), e19-29. 
Slack, T. (2010s). Work in rural America in the era of globalization. In C. Bailey, L. Jensen, \& E. Ransom (Eds.), Rural America in a globalizing world: Problems and prospects for the 2010s (pp. 573-590). Morgantown, WV: West Virginia University Press.

Slack, T., Thiede, B. C., \& Jensen, L. (2020). Race, residence, and underemployment: Fifty years in comparative perspective, 1968-2017. Rural Sociology. https://doi.org/10.1111/ruso.12290.

Smith, K. E., \& Tickamyer, A. R. (2011). Economic restructuring and family well-being in rural America. University Park, PA: The Pennsylvania State University Press.

Stein, E. M., Gennuso, K. P., Ugboaja, D. C., \& Remington, P. L. (2017). The epidemic of despair among white Americans: Trends in the leading causes of premature death, 1999-2015. American Journal of Public Health, 107(10), 1541-1547.

Strine, T. W., Beck, L. F., Bolen, J., Okoro, C., Dhingra, S., \& Balluz, L. (2010). Geographic and sociodemographic variation in self-reported seat belt use in the United States. Accident Analysis and Prevention, 42(4), 1066-1071.

Thiede, B., Kim, H., \& Valasik, M. (2018a). The spatial concentration of America's rural poor population: A postrecession update. Rural Sociology, 83(1), 109-144.

Thiede, B. C., \& Monnat, S. M. (2016). The great recession and America's geography of unemployment. Demographic Research, 35, 891-928.

Thiede, B. C., Lichter, D. T., \& Slack, T. (2018b). Working, but poor: The good life in rural America? Journal of Rural Studies, 59, 183-193.

Vierboom, Y. C., Preston, S. H., \& Hendi, A. S. (2019). Rising geographic inequality in mortality in the United States. SSM - Population Health, 9, 100478.

Woolf, S. H., \& Schoomaker, H. (2019). Life expectancy and mortality rates in the United States, 19592017. JAMA, 322(20), 1996-2016.

Yang, T.-C., Jensen, L., \& Haran, M. (2011). Social capital and human mortality: Explaining the rural paradox with county-level mortality data. Rural Sociology, 76(3), 347-374.

Publisher's Note Springer Nature remains neutral with regard to jurisdictional claims in published maps and institutional affiliations.

\section{Affiliations}

\section{Shannon M. Monnat ${ }^{1}$}

Shannon M. Monnat

smmonnat@maxwell.syr.edu

1 Lerner Center for Public Health Promotion \& Department of Sociology, Maxwell School of Citizenship and Public Affairs, Syracuse University, Syracuse, NY 13240, USA 